OECD Economics Department Working Papers No. 70

\title{
On the Sequencing of Structural Reforms
}




\section{OECD \\ DEPARTMENT \\ OF ECONOMICS AND STATISTICS}

\section{WORKING PAPERS}

No. 70 ON THE SEQUENCING OF STRUCTURAL REFORMS

by

Sebastian Edwards

September 1989

$$
\begin{aligned}
& \text { (0)BDE } \\
& \text { 05CD } \\
& \text { (0) }
\end{aligned}
$$


, 
GENERAL DISTRIBUTION

\title{
ECONOMICS AND STATISTICS DEPARTMENT
}

\author{
WORKING PAPERS
}

This series of Working Papers is designed to make available, to a wider readership, selected studies which the Department has prepared for use within OECD. Authorship is generally collective, but main individual authors are named. The Papers are generally available in their original language. English or French, with a summary in the other.

Comment on the papers is invited, and may be sent to OECD, Department of Economics and Statistics, 2 rue André Pascal, 75775.Paris Cedex 16, France. Additional copies of the Papers on a limited basis can be forwarded on request.

ORGANISATION FOR ECONOMIC CO-OPERATION AND DEVELOPMENT 
Both OECD and developing economies have embarked on structural reforms aimed at dismantling regulations and reducing the extent of distortions affecting different sectors of their economies. Regardless of the marked differences, both groups have to deal with the problems of the appropriate sequencing and speed of reforms. This paper first critically reviews the LDC related literature on sequencing and speed of structural reforms drawing out features which are of relevance for OECD economies. The paper then develops a formal framework based on a welfare criterion for evaluating different sequencing scenarios. The framework emphasises the microeconomic or efficiency effects of structural policies paying particular attention to the way in which distortions interact both intra and inter temporally. The framework is then used to discuss some of the important issues such as the sequencing of micro and macro reforms ("competition of instruments"), broad front versus sequential reforms, and the role of policy credibility.

$$
* * * * * * *
$$

Un grand nombre de pays de l'OCDE et de pays en développement se sont lancés dans des réformes structurelles destinées à démanteler les réglementations et à réduire les distorsions qui affectent certains secteurs d'activité. Bien que très différents, ces deux groupes de pays se trouvent confrontés à un même problème, qui est celui du choix du calendrier et du rythme de mise en oeuvre de ces réformes. Le présent document commence par une analyse critique des études consacrées à ce sujet pour les pays en développement et en fait ressortir les points qui présentent un intérêt pour - les pays de 1'OCDE. Il présente ensuite un cadre formel, fondé sur un critère de bien-être, pour évaluer différents calendriers hypothétiques de mise en oeuvre des réformes. Ce cadre privilégie les effets micro-économiques ou l'efficience des politiques structurelles, une attention particulière étant accordée aux interactions intratemporelles et intertemporelles des distorsions. Il est ensuite utilisé pour examiner certaines questions importantes comme la succession de réformes micro-économiques et macro-économiques ("concurrence entre instruments"), les avantages et inconvénients respectifs des réformes d'ensemble et des réformes progressives, ainsi que l'importance de la crédibilité des mesures de politique économique. 
ON THE SEQUENCING OF STRUCTURAL REFORMS

by

Sebastian Edwards*

* Sebastian Edwards, from the University of California, Los. Angeles, and the National Bureau of Economic Research, prepared this paper while consultant to the OECD. The author thanks Hartmut Fest and the participants of a seminar at the OECD for helpful comments. He also gratefully acknowledges the excellent assistance and detailed comments he received from Miguel Savastano. The views expressed reflect the author's opinion and do not necessarily represent those of the OECD or the governments of its Member countries. 


\section{Table of Contents}

Page

1. Introduction

2. On the Sequencing and Speed of Reform: A Critical Review of the LDCs Literature

3. An Intertemporal Framework For Analyzing the Welfare Effects of Structural Reform

3.1 The Analytical Framework

3.2 The Key Distortions

3.3 The Interaction of Key Distortions

3.4 Extensions of the Basic Framework: Competition of Instruments and Credibility

4. The Welfare Effects of Structural Reforms: Some Illustrations Based on OECD-type Economies

4.1 The Dynamics of Structural Reforms of Product Markets

4.2 Relaxing Capital Controls

4.3 Synthesis

5. General Features of Alternative Sequencing Strategies, Policy Implications and Recommendations for Future Work

5.1 Broad Front vs. Sequential Concentrated Approaches

5.2 Abrupt or Gradual Reforms?

5.3 Macro vs. Micro Reforms: Does the Order Matter?

5.4 Where Do We Go From Here?

Appendix A: A Real Intertemporal General Equilibrium Model of

Structural Reform
A.I Introduction
A.II The Model
A.III The Welfare Effects of Liberalization and Deregulation
A.IV Evaluating Alternative Sequencings of Reform
A.V Extensions

Appendix B: Sector Specific Labor Market Distortions: A Diagramatic Exposition 


\section{Introduction}

In the last decade or so a large number of countries .. both developed (i.e., OECD) and developing -. have embarked on structural reforms aimed at dismantling regulations and reducing the extent of distortions affecting the different sectors of their economies. Although the ultimate motivation for these reforms is similar .- the improvement of economic performance - the OECD and the less developed countries (LDCs) face, in many respects, different problems. The initial conditions, the institutional settings, the extent of the distortions, and the macroeconomic environment in the OECD countries are markedly different than in the LDCs. However, both groups of nations have to deal with the problems of the appropriate sequencing and speed of reform. Basically, there are two interrelated questions (1) in what order should markets be deregulated and liberalized; and (2) what is the optimal speed of reform (i.e., overnight vs. gradual).

The differences between the problems faced by OECD and LDC countries can be illustrated with two examples. In many LDCs, the trade regime has many times been liberalized without an accompanying macroeconomic structural reform which would ensure the necessary movement of the real exchange rate. This has in some instances led to quite disastrous macroeconomic consequences and a call for the policy to be ended. For OECD economies, in turn, micro-structural reforms are the ones more urgently required. In these countries, for example, privatization has in some instances not been accompanied (preceded) by policies aimed at changing the competitive environment through the lifting of barriers to entry to the different markets, and/or by the relaxation of restrictive trade policies. 
During the last few years a relatively large literature on the dynamics of structural reform has developed. ${ }^{1}$ Mast of this literature, however, is concerned with the developing countries and sets the problem in a context where severe macroeconomic disequilibriums coexist with serious microeconomic distortions. The existing literature has mainly discussed problems related to: (1) the order of liberalization of the capital and current accounts of the balance of payments, and (2) the optimal speed of economic reform. A small number of papers have dealt, in addition, with broader issues related to the design of structural reforms in a setting linvolving a larger number of markets. 2

In spite of its speciffcity, the LDCs related literature contains some elements that are of help for the design, evaluation, and monitoring of structural reform in more advanced economies such as those of the OECD countries. For example, some of the more recent LDC related 11terature has dealt with dynamic problems that explicitly highlight the roles of savings and investment in the adjustment process prompted by real shocks; also the discussions on the optimal speed of reform and on the issues of credibility, time consistency and reputation contain insights that can be used, after some adaptations, in the analysis of OECD cases. Also the incorporation of adjustment costs and hysteresis effects are of relevance for the more advanced nations. Finally, the idea of "competition of instruments" is important to understand the tradeoffs faced by policymakers in almost any setting.

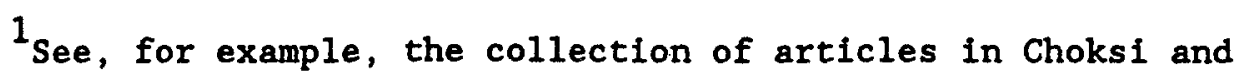
Papageorgiou (1986).

${ }^{2}$ See, for example, Krueger (1986). 
The purpose of this paper is threefold. First it critically reviews the $L D C$ related literature on sequencing and speed of structural reforms. This review tries to determine what elements from this literature can be used in a broader analysis that is of relevance for the more advanced nations; also some of the empirical and policy applications of this literature are discussed. Second, this paper develops an analytical framework. that is helpful for analyzing, the dynamics of structural reforms in the OECD countries. Here the differences between OECD and LDCs countries regarding the macroeconomic environment, the initial conditions and the prevaliling distortions play an important role. The framework is based on a welfare criterion for evaluating different sequencing scenarios. Although for tractability reasons the formal model developed here ignores adjustment costs and uncertainty, we do provide a fairly detailed discussion on how these issues could affect policy design and evaluation. Moreover, in doing this we draw extensively from the experiences of the developing countries both with unilateral reforms as well as with liberalization attempts sponsored by the World Bank. The third objective of the paper is to illustrate the usefulness of this framework for the case of the OECD economies. Although the formal analysis focuses, almost exclusively, on the microeconomic aspects of reform, we also provide a discussion of some of the more important policy aspects related to the sequencing of micro and macro reforms. Here the concept of "competition of instruments" is developed. Finally, the paper contains two technical appendices that provide the formal underpinnings of our analysis. 


\section{On the Sequencing and Speed of Reform: A Critical Review of the LDCs Literature}

Traditionally, researchers dealing with structural reforms in the LDCs have addressed some of the problems related to the sequencing and speed of liberalization. The discussion has focused on three issues: (1) the order of liberalization of the capital and current accounts of the balance of payments; (2) the sectoral order of liberalization of the trade account (i.e., whether tariffs should be reduced in all sectors simultaneously or in some alternative way); and (3) the appropriate speed at which trade reform should be carried out. However, most studies have 1gnored issues related to capital markets and labor markets distortions. ${ }^{3}$ This section of the paper reviews the more important analytical pieces that have dealt with the sequencing problem, emphasizing their policy implications. A brief discussion of some historical -. or empirical -. policy applications of these principles in a number of developing nations is then provided. Finally, the usefulness of this literature for the case of more advanced nations, such as the OECD countries, is critically evaluated.

\section{Adjustment Costs and Capital Inflows}

Little, Scitovsky and Scott (1970) were the first to address some of the issues related to the speed and order of liberalization. Their analysis was mainly based on political economy considerations, and their basic recommendation was that structural reforms should be carrled out gradually. The reason for this resides on the role of adjustment costs, and on the opposition to the reform policy that these costs can generate. According to these authors faster reforms will result in larger short term costs .. including unemployment and bankruptcies .. and thus in a stiffer political opposition.

${ }^{3}$ Exceptions are McKinnon (1973) and Krueger (1986). 
Along similar lines, Michaely (1982) has argued that in order to minimize the political opposition to trade reform it is neçessary to minimize the short run unemployment effects and other adjustment costs associated with these policies. According to some authors, one way of reducing these adjustment costs is by relying on foreign capital during the transition. Clark (1986), for example, has argued that the Egyptian structural reforms of the 1970s succeeded thanks to the ample availability of foreign funds that helped achieve a smoother transition.

Anne Krueger has also, and repeatedly, argued that an increased reliance on foreign funds will greatly reduce the frictions that emerge during major structural reforms. ${ }^{4}$ In fact, in her recent writings on possible solutions to the debt crisis, Krueger has strongly argued that the multilateral institutions should provide large financial assistance to those indebted developing countries committed to reforming their external sectors (see Krueger 1988).

A common thrust of the view that argues for financial assistance during the transition is that since the adjustment cost associated to micro reforms can be reduced by an increased availability of foreign funds, restrictions on the importation of capital should be reduced before the trade reform takes place. 5 That is, in a way this view calls for a "capital account first" sequence of structural reform.

\footnotetext{
${ }^{4}$ Krueger (1981, 1984).
}

${ }^{5}$ The key here is the assumption that capital controls are precluding capital inflows. This, of course, need not be the case. Moreover, it will not be the case in those countries where the domestic financial sector is repressed. Thus, the proposed sequencing assumes that the domestic financial sector is liberalized before either the trade or capital account. On this see, for example, Mathieson and Mckinnon (1981) and Edwards (1984). 
Capital Inflows, the Real Exchange Rate and Competitiveness

Ronald Mckinnon has, perhaps, been the strongest opponent to the view that structural (and mainly trade) reforms should be accompanied by capital inflows. In his classical study on the role of financial markets in the development process Mckinnon (1973) provided the first significant and comprehensive analysis of the order of liberalization. His analysis focused on the "competition of instruments" problem and greatly emphasized the role played by the real exchange rate. Mckinnon argued that capital account restrictions should be relaxed only after trade and other industrial sector distortions had been dismantled. The reason for this is that capital inflows will result in a real exchange rate appreciation which, in turn, deprotects the tradables sector at a time when, due to the tariff reduction reform, a real exchange rate depreciation is needed. ${ }^{6}$ According to Mckinnon, "unusually large capital inflows of forelgn capital ... Inhibit the exchange rate to depreciate sufficiently ..." (1973, p. 160). This problem is compounded by the fact that these flows are unsustainable in the long run. Consequently, he argues, a structural reform of the trade account should "deliberately avoid an unusual or extraordinary injection of foreign capital" (1973, p. 161).

Edwards (1989b) has recently developed a formal intertemporal real equilibrium model to analyze the way in which the equilibrium real exchange rate reacts to a reduction in tariffs and to a capital account liberaliza. tion. He shows that in a world with three goods (exportables, importables and nontradables) a reduction in tariffs can, in general, result in either

${ }^{6}$ The fact that capital inflows result in a real exchange rate appreciation has been investigated extensively within the context of the Dutch-disease effects of foreign aid. See, for example, van Wijnbergen (1986). 
an equilibrium real exchange rate depreciation or appreciation. Capital account liberalization, however, will unambiguously result in a real exchange rate appreciation. This analysis, then, shows that theoretically there is some support for McKinnon's contentions. Furthermore,'Edwards (1989a) has recently used a 12 LDCs data set to empirically investigate the way in which the equilibrium real exchange rate reacts to tariff changes and changes in capital flows, among other variables. He found that higher tariffs resulted in an equilibrium real exchange rate appreciation, as did increases in capital inflows.

In a number of later writings McKinnon has again addressed the general issues of sequencing and speed of structural reform. In his recent evaluation of the overall experiences of the Southern Cone countries with structural reform in the 1970s, Mckinnon (1982) has argued that Chile's superior performance was due to having maintained the capital account closed while tariffs were reduced. He contrasted this case to Argentina's dismal performance and argued that the fact that Argentina had followed the opposite sequencing was at the heart of the explanation. Moreover, he used these episodes to conclude that trade liberalization should only take place after the fiscal deficit is eliminated. In this way the government will face no need to borrow from abroad to finance its expenditure and, thus, the need for capital inflows during the transition will be reduced.

\section{Welfare Effects and Credibility}

In a series of papers Jacob Frenkel (1982, 1983) discussed the appropriate order of structural reform. He emphasized the welfare consequences of alternative orderings of liberalization as well as the different nature of the adjustment of goods and capital markets. His discussion was partially based on the Southern Cone reforms of the early 1970s. Frenkel 
made the Important point that goods and asset markets clear at different speeds. While asset markets clear almost instantaneously, the attainment of equilibilum in the goods markets usually takes some time. Thus, Frenkel argued, a synchronization of the structural reform process will call for the goods markets (i.e., the current account) to be liberalized before the capital account. Also, Frenkel polnted out that from a purely welfare perspective, second best considerations suggest that it is more advisable to open the current account before liberalizing restrictions on capital mobility. Frenkel says that "a comparison of the costs of distortions ... supports the proposition that the trade account should be opened first" (1983, p. 167). His analysis, however, does not include a formal discussion of this proposition.

A common concern of most authors has to do with the survivability of a structural reform attempt. ${ }^{7}$ An important determinant of such survivability is the extent to which the reform program is credible. If there is no credibility and the public expects the liberalization measures to be reversed, it will actually take steps that will undermine the effectiveness of the reform program. Calvo $(1983,1987)$ and Stockman (1982) have dealt systematically with the role of credibility in the liberalization process. In particular Calvo (1987) has emphasized that if a specific reform is not credible to economic agents, liberallzing other sectors may actually be welfare reducing. A good examplo of this would be to liberalize the capital account at a time when the public belleves that the trade reform will be reversed -. that 1s, when the credibility of the trade reform is low. According to Calvo, under these clrcumstances the public will use foreign

${ }^{7}$ See, for example, Little et al. (1970), Michaely (1982, 1987). 
funds . that have been made available through the liberalization of the capital account .. to import larger amounts of goods, especially durables, than what would be called for if the trade reform were credible. This "over-importation" will result in welfare losses, since the lack of credibility has played the role of a distortion. Since under these circumstances the liberalization of the capital account magnifies the pre-existing distortions, (i.e., taxes or tariffs), Calvo recommends that in countries where governments lack credibility, capital controls should not be removed until the trade liberalization program is fully consolidated.

As has been said, most of the studies reviewed above deal with the rather narrow issue of the order of liberalization of the current and capital accounts of the balance of payments, without addressing the sequencing problem from a brosder perspective. An exception to this is Krueger (1984, 1986) who provides a comprehensive discussion that deals with labor markets, the agricultural sector and the trade and capital accounts. She argues that the most serious problem with a liberalization program is the political resistance that it generates. Economic agents can generally recognize the short run adjustment costs assoclated with structural reforms, but usually have difficulties perceiving its long run benefits. In terms of the appropriate sequencing, Krueger is not fully committed. While, on the one hand, she argues for increased capital inflows during the transition of a trade-related structural reform, on the other, she points out that opening up the capital account in the presence of trade distortions may result in a serious misallocation of Investment (Krueger 1986). Regarding the speed of structural reform, however, Krueger is quite emphatic in advocating a rapid dismantling of distortions. This recommendation, she argues, is dictated both by welfare as well as credibility considerations. 


\section{World Bank Studies}

Some international institutions have also shown concern regarding the appropriate sequencing of liberalization. The World Bank, for example, has supported a number of projects on the area. This discussion was initiated by Edwards (1984) and followed up by Edwards and van Wijnbergen (1983, 1986). These authors constructed a formal general equilibrium intertemporal model to analyze the appropriate speed and order of liberalization. They assume a 2-period economy with tariffs and distorted investment decisions. On welfare grounds they show that in this setting a slow (gradual) trade reform is preferable to an abrupt one. The reason for this is that by liberalizing slowly present-period savings increase, reducing the extent of the existing distortion. They also argue that on second best grounds the most appropriate sequencing consists of liberalizing the current account before opening up the capital account. Rodrik (1987) extended this framework by adding two additional distortions: a minimum wage and a fixed price of nontradables. As Edwards and van Wifnbergen, however, he concentrates on the trade and capital accounts of the balance of payments. Rodrik concludes from 'hi's analysis that the sequencing suggested by Edwards and van Wijnbergen is the most adequate one.

The by-now famous 1985 World Bank Conference on the dynamics of structural reform included important contributions by Krueger (overali issues), Mussa (on the speed of liberalization), Michaely (on speed and order within the trade account), Edwards (sequencing of the reforms) and Harberger (on the role of the capital account), as well as commentaries by McKinnon, Balassa, Lal and Dornbusch (see Choski and Papageorgiou (1986)). These papers dealt mainly with analytical issues, without looking at the empirical evidence. The main conclusions that emerged from this conference 
was that although theoretically little was known on the dynamics of structural reforms, the fate of these liberalizations many times depended on implementing a package that included an appropriate speed and sequencing of the reforms. With regard to the former issue, no unique policy conclusion was obtained, while there was widespread agreement that the most appropriate sequencing of reform would postpone capital account liberalization until the trade reform was completed. The reasons for this recommendation were related to: (a) the effects on the real exchange rate of alternative components of the structural reforms; (b) adjustment costs and political economy considerations; and (c) welfare considerations. Deepak Lal (1986), however, maintained a dissenting view, arguing that a freely floating exchange rate would be an important .- indeed crucial -- component of a liberalized or reformed economy. Since an important requirement for having a genuine floating system is to have, at least to some extent, a convertible currency, Lal argued that the approprlate order would imply opening up the capital account before reforming micro decisions via the reduction of import tariffs. In a recent contribution Sell (1988) has developed a simple formal framework to analyze this issue. He uses Dornbusch (1974) static three goods model (with exportables, nontradables and importables goods) to investigate the way in which tariff reform affects other relative prices and the equilibrium real exchange rate. As in Dornbusch's original discussion, he finds that the degree of substitutability (or complementarity) between the three goods is an important determinant of the way the tariff reform will affect the equilibrium real exchange rate. He argues that since in theory a trade liberalization can result in either a real depreciation or a real appreciation it is convenient to adopt a floating exchange rate before the trade reform is initiated. Sell, then, 
sides with Lal arguing in favor of the "capital account first" sequencing.

The 1986 World Bank Conference on labor markets and trade organized by C. Lluch and R. Klinov dealt specifically with the role of labor market distortions in structural reforms. The studies presented at this conference emphasized the potential unemployment effects of structural reforms and discussed possible ways to reduce this problem, including retraining grants, deindexation of wages and dismantling of other rigidities in the labor market. Here Edwards (1988a) argued that a gradual trade reform would generally reduce unemployment dislocations. The other papers delivered at this conference did not tackle, however, the issue of sequencing of reform.

In an important World Bank study on trade and Industrial policy in East Asia, Bhattacharya and Iinn (1988) have briefly dealt with the appropriate order of reforms. In a nutshell they have argued that: (1) real sectors should be liberalized before financial sectors; (2) domestic financial markets should be liberalized prior to opening the capital account; and (3) barriers to international trade should be removed before lifting capital controls.

Finally, the gigantic project directed by Michaely, Choksi and Papageorgiou has recently reviewed the liberalization episodes of 19 countries. Although the final findings of this study have not yet been made fully available, the interim reports (Michaely, et al. (1986) highlight a number of very important facts. First, the authors found that macroeconomic instability was the single most important cause behind reversal of trade reforms. Second, in these countries trade related structural reforms generated no significant unemployment consequences. And third, those countries that could not sustain a trade liberalization process corresponded to those nations that had experienced a significant real exchange rate appreciation. 
An accompanying study dealing with a smaller number of countries -Argentina, Chile, Uruguay and Colombia -. confirmed the view that capital inflows (outflows) usually result in real exchange rate appreciation (depreciation). These findings, then, provide additional support to the view that argues for postponement of capital account deregulation on the grounds that this policy induces real exchange rate overvaluation and loss of competitiveness in the tradables sector.

\section{IMF Studies}

Studies supported by the IMF, have also dealt with some sequencing issues. Khan and Zahler (1983, 1985, 1987) constructed a simulation model to analyze the consequences of alternative liberalization sequencings. As In Frenkel's discussions $(1982,1983)$ their model assumes that financial markets adjust much faster than goods markets. They found that over the longer run alternative orders of liberalization did not make significant differences in terms of the behavior of real output and relative prices. Another important finding of these studies is that a consistent macroeconomic policy is imperative in any reform aimed at liberalizing the current and capital accounts. In a recent IMF Occasional Paper, Corden (1987) also addresses the question of the appropriate sequencing of structural reform in the LDCs and concludes that "opening up the domestic capital market to the world is likely to make it more difficult to manage the exchange rate"; as a consequence, this will "present problems if it is desired to fine tune the exchange rate as part of a major trade liberalization" (Corden 1987, p. 23). Thus, argues Corden, the adequate sequencing should postpone the liberalization of the capital account.

In the most recent effort from the IMF, Bhandari (1988) has developed a model with well-developed real and financial sectors to explicitly analyze 
the issue of the adequate liberalization sequencing. Contrary to other authors, Bhandari models capital controls using a dual exchange rate regime characterized by a fixed nominal rate for commercial transactions and a freely fluctuating rate for financial transactions. He argues that an appropriate criterion for selecting a specific sequencing over another one is the way the economy's degree of competitiveness evolves. He then shows that in his model almost anything can happen and, thus, that "if the policymakers' preference function is defined in terms of the adjustment of prices, output and the commercial real exchange rate, it is clear that a general unqualified statement regarding the sequencing of commercial versus financial reform is not available" (p. 3).

\section{Macroeconomic Effects of Alternative Sequencings}

More recently, a new dimension has been added to the policy debate on sequencing of liberalization in the developing countries. As a result of the macroeconomic dislocations provoked by the debt crisis of the early 1980s a number of authors, and certainly the multilateral institutions, have begun to investigate the interaction between structural reforms and macroeconomic stabilization programs. Most contributions to this emerging literature have dealt with the sequencing of stabilization and liberalization policies, discussing whether liberalization should be undertaken before, simultaneously or after disinflation is attained. As can be seen in Table 1, this literature has provided a number of insights and a myriad of policy recommendations, that go from "liberalize first" to "stabilize first".

Those authors that favor the "liberalize first" strategy or the simultaneous implementation of both policies include Krueger (1981, 1984 , 1988), Michaely (1987) and Corden (1987). They argue that there is little connection between disinflation and liberalization policles, and that the 
TABLE 1

Schematic View of the Literature on The Sequencing of

Stabilization and Trade Liberalization

1. Trade Liberalization First

Krueger (1981) If there are foreign funds available tariffs can be reduced without an accompanying real depreciation, helping the stabilization effort by providing an anchor for (many) domestic prices.

2. Simultaneous Implementation of Both Policies

Krueger (1981) In theory there is very little connection between the determinants of inflation and of the orientation of the trade regime. It is possible to attack both problems at the same time as long as we avoid real overvaluation.

Krueger (1984) Postponement of liberalization implies prolonging inefficiency costs. Do it simultaneously following crawling peg and assuming that government will not resort to controls in an effort to curb inflation.

Michaely (1987) Liberalization will only succeed with depreciated RER. This requires solving fiscal deficit pressures simultaneously.

Corden (1987) As long as overvaluation is avolded it is possible to carry on both policies at the same time.

\section{Stabilization First}

McKinnon and Mathieson (1981) Liberalization w1ll have a better chance of succeeding if undertaken with a fiscal surplus. In this way we can assure that we will maintain a depreclated RER.

Mckinnon (1984) Main problem with aborted liberalizations is that they have been accompanied with massive capital inflows that resulted in real appreciation. Best way to avoid need for forelgn funds is to achleve fiscal surplus prior to liberalizing.

Fischer (1986, 1987) Since inflation generates serious distortions, liberalization will take place under inappropriate signals. Thus, inflation should be brought down first.

Sachs (1987, 1988) Both policies result in a "competition for instruments", where what is required to succeed in one front is the opposite of what is needed to succeed in the other. Historical evidence from successful Asian exporters suggests stabilization should be consolidated before attempting trade reforms. 
costs of trade restrictions are too high to justify the postponement of liberalization until the macroeconomy has regained equilibrium. They are careful to point out, however, that in order to ensure the success of the trade reform, it is crucial to avoid real exchange rate overvaluation. The supporters of the "stabilization first" sequence include Sachs (1987, 1988), McKinnon (1984) and Fischer $(1986,1987)$. They have based their views on a number of considerations, including the historical difficulty of avoiding overvaluation in countries with high fiscal deficits, and the relation between inflation, relative price variability and resource allocation. A limitation of much of this literature, however, is that it is very general and that no systematic attempt has been made to analyze the historical evidence. Moreover, most of these studies have not made a clear distinction between different degrees of trade reform, or between different initial types of macroeconomic disequilibria.

\section{Empirical Evidence on Structural Reforms}

Although the LDC related literature on structural reforms has been quite rich in analytical insights, relatively little empirical work has been undertaken on the subject. In terms of ex-post explanations of the outcome of reforms, a considerable number of authors have discussed the experiences of Argentina, Chile, and Uruguay. Some of the works in this area include those of Mckinnon (1982), Harberger (1982), Dornbusch (1982, 1985), Calvo (1983, 1986), Corbo and de Melo (1985, 1987), Balassa (1982a,b), Edwards $(1985,1986)$ and Edwards and Cox-Edwards (1987). The Chilean experiment offers some important lessons for the sequencing debate. First, this episode shows that the destabilizing effects of massive capital movements are much greater than what most observers initially thought. With hindsight we can say that in the Chilean case it would have been advisable to distance 
even more in time the two reforms.

More generally, the experience suggests that in countries whose initial conditions resemble those in Chile in the early 1970s, the capital account should be opened rather slowly and after "sufficient" time has elapsed since the trade reforms have been completed. Of course, it is not possible to state in a precise fashion what "sufficiently after" means. Policymakers, however, should monitor real exchange rate movements and the external sector behavior when deciding how and when to relax controls on capital movements. Second, the Chilean experiment clearly shows that the destabilizing effects of massive capital movements are greatly magnified in the presence of other distortions like legally imposed wage rigidities. And third, this experience highlights the crucial role of credibility in the success of an economic reform. As was said before, if the public believes that the reform attempt will be reversed, it will act accordingly and may even be able to frustrate the whole liberalization reform. In the Chilean case the combination of marked real exchange rate overvaluation and a passive government macroeconomic policy undermined the public's credibility on the maintenance of both the exchange rate and tariffs policy. In fact, it is in the credibility sphere where the most important lesson on the sequencing of liberalization lies; in a sense, the implementation of a consistent and credible policy package turns out to be more important than determining "the correct" order of liberalization (see Edwards and Cox Edwards, 1987, and Corbo and de Melo, 1987).

The experiences of the Southern Cone have been used in policy evaluation and design in other countries. For example, some authors have argued that in order to avold the Southern Cone fate, Korea should postpone the opening of the capital account. Although at this time there are no writings available to the public, policymakers in Ecuador, Bolivia and 
Mexico have seriously studied the existing Southern Cone literature to design their structural reform policies.

\section{$\underline{\text { Summary }}$}

The brief review presented in this section accurately reflects the large amount of work and energy being devoted to analyzing sequencing issues within the context of the LDCs economies. Some of the insights developed in these papers are, clearly, of interest for the most advanced nations. First, the idea of "competition of instruments", which is closely related to the concept of "policy dilemma" developed in the 1960s, has a universal application. Second, the preoccupation with the real exchange rate as a crucial relative price is also relevant for the industrialized countries. Indeed an important point recently made by a number of authors, including Dornbusch, Williamson and Feldstein, is that real exchange rate disequilibriums -. or real exchange rate misalignments - can be very costly for the advanced nations. On the other hand, it is clear that the more advanced nations have more mechanisms at their disposal to avoid serlous real exchange rate disequilibrium. This means that although RER considerations should still be present in discussions regarding $O E C D$ countries, they should play a less central role than in the LDCs analyses. Also, OECD related analyses should clearly downplay the role of macroeconomic instability, a topic of paramount importance in Latin America, but of less importance in most countries of the industrial world. From the perspective of the OECD countries, we can also identify some limitations of the literature reviewed above: (1) most contributions do not develop (or use) an explicit intertemporal framework where investment and saving decisions play an important role. (2) The discussions deal, almost exclusively, with the liberalization of the trade and capital accounts of the balance of payments. (3) Most studies assume, implicitly or explicitly, 
that the domestic (e.g., nontradables) markets are not distorted. This, of course, is a gross oversimplification since in most countries some of the key service sectors, including telecommunications and transportation, are quite heavily regulated. (4) The nature of the capital controls is rarely specified, and (5) Labor markets are almost always ignored, assuming implicitly that they are free of distortions. This, of course, may constitute a restrictive assumption for the cases of both developed and developing countries.

In the rest of this paper we will develop an explicitly intertemporal framework to analyze some important issues related to sequencing of reform for the case of more advanced nations. In doing this the relevant insights from the IDC related literature mentioned above will be incorporated. 


\section{An Intertemporal Franework for Analyzing The Welfare Effects of Structural Reform}

The purpose of this section is to present a simple analytical framework suitable for analyzing the welfare consequences of structural reforms in developed economies. The discussion is quite general and avoids unnecessary technicalities; most of the analysis is, in fact, carried out verbally and with the aid of some diagrams. This general framework can then be adapted to look at specific cases of structural reform. In Appendix A, however, a mathematical representation of this framework is provided, and some specific exercises are formally presented. This model is then used to discuss the welfare implications of alternative sequencings of reform.

Since our analysis focuses on structural reforms, the framework presented emphasizes the microeconomic or efficiency effects of such policies, giving a minimal role to macroeconomic aspects. This is, in fact, a fairly accurate representation of most of the OECD countries that have already attained macroeconomic stability. Macroeconomic aspects are discussed in greater detail in Section 5 where some recent evidence on World Bank structural adjustment loans is reported. This section is organized as follows: first the bare bones of the analytical framework are presented. Second, we explain the key distortions considered in our analysis. Third, we discuss how these different distortions interact among themselves; here we place special emphasis on the relation between intratemporal and intertemporal distortions. And fourth, we discuss two important issues related to the sequencing of reforms that are not captured in a formal way by our model: the problem of competition of instruments and the role of credibility. 


\subsection{The Analytical Framework}

We will consider an open economy with three broad production sectors: an import competing sector $(M)$; an exports sector $(X)$; and a nontradables sector (N). The latter can be interpreted as a service sector that includes industries such as transportation and communications. Output of $X, M$, and $N$ is produced by many competitive firms. There are three factors of production -- labor, natural resources and capital -- and consumers in this economy consume all three goods. ${ }^{8}$ We further assume that the country is small within the context of the world economy and, thus, that it faces given world prices of importables and exportables. 9

The simplest way to explicitly incorporate intertemporal effects of different policies into this analysis is to consider the existence of two periods - - the present (period 1) and the future (period 2). Consequently, all economic agents in this economy face an intertemporal budget constraint that restricts the present value of income to being equal to the present value of expenditures. In a particular period, however, income can exceed (fall short of) expenditure; as a consequence in any one period the current account of the balance of payments can be in deficit (surplus). The intertemporal nature of the model allows us to focus formally on savings and investment decisions and, thus, to define the current account as the difference between savings and investment. While the current account balance can be different from zero in any period, the intertemporal budget constraint

${ }^{8}$ Formally, consumers in this economy maximize a time separable intertemporal utility function, where each subutility function depends on that period's consumption of X, M and N. See Appendix A.

${ }^{9}$ If, alternatively, we assume the case of a large country we will need to determine the price of $X$ and $M$, as well as the interest rate, endogenously. Although this implies a substantial complication in the algebra, the main thrust of our arguments will not be affected. 
requires that the discounted sum of the current account in both periods adds up to zero. The nontradables goods sector, however, will be assumed to be permanently (e.g., in every period) in equilibrium.

\subsection{The Key Distortions}

We assume that distortions are present in four markets: (1) Imports are assumed to be subject to (relatively low) tariffs ( $t$ ). (2) We assume that the labor market is subject to some types of regulations. In terms of our model the easiest way to think about this is by assuming the existence of a rigid wage rate set above the market clearing wage rate. This can be interpreted as having a union-determined or an administratively-set minimum wage. Moreover, we assume that this minimum (or rigid) wage is set in terms of the exportable good. This, in turn, can be interpreted as a 1008 indexation mechanism where the price of $X$ is used as the index for wage adjustment. ${ }^{10}$ Naturally, all of this results in unemployment. In order to simplify the discussion, we follow the traditional international trade literature and assume that in each period the supply of labor is inelastic. ${ }^{11}$

Initially we will assume that this rigid or minimum wage (i) affects the economy as a whole and that it is in effect in both periods. (3) We assume that regulations on the nontradables sector take the form of a tax $\tau$, that introduces a wedge between the producer and consumer prices. (4) Finally,

${ }^{10}$ On labor market regulations in OECD countries see Chan-Lee, Coe and Prywes (1987). The assumption that the minimum wage is set in terms of the numeraire is made for presentation convenience; it greatly facilitates the diagrammatical analysis that follows. Alternatively one could assume that the minimum wage is set in terms of a basket of goods. In this case $-\hat{\pi}$, where $\hat{W}$ is the change in the nominal wage and where $\hat{\pi}$ is the percentage change in the (exact) consumption price index. The results obtained in this case will depend on the weights given to the different goods in the price index. See Edwards (1988a).

11 Assuming a positively sloped supply of labor will not change the analysis in significant ways. See Edwards (1989d). 
regulations in the financilal sector are assumed to result in a domestic (real) interest rate that differs from the world interest rate. The most convenient way to formally deal with these types of regulations is by assuming that there are capital controls in the form of a tax on foreign borrowing $(\sigma)$. Consequently the domestic (real) interest rate ( $r$ ) will be equal to the world rate $\left(r^{*}\right)$ plus this tax $\left(r-r^{*}+\sigma\right)$. One of the exercises to be performed below will consist then on a reduction of $\sigma$. An important characteristic of the domestic interest rate is that it is expressed in terms of tradable goods and not in terms of a basket of all goods consumed; as a result of this, there is a difference between the (real) interest rate $r$ and the consumption rate of interest. ${ }^{12}$

The way in which these distortions affect the four markets can be conveniently captured diagrammatically. In fact, as will be seen below, it is possible to represent most of the welfare effects of different structural reforms with the aid of these figures. The diagrammatical representations of the importables and nontradables markets and of the saving-investment equilibrium are the usual ones and are presented in Figure 1. Panel A represents the importables market in period 1 where $P_{M}$ is the domestic price of importables and $p_{M}^{*}$ is the world price $\left(p_{M}-p_{M}^{*}+t\right) .{ }^{13}$ Panel $B$ is the nontradables market (in period $i$ ), where, $r$ is the tax on nontradables that introduces a wedge between the production and consumption prices. Finally, panel $C$ shows the interaction between savings and investment, where $r *$ is the (exogenously determined) world interest rate and $r$ is the domestic real

${ }^{12}$ See, for example, Dornbusch (1983a).

${ }^{13}$ Our discussion will focus on import tariffs but could easily deal with the (realistic) case of export subsidies. It should be noted, however, that * in an intertemporal setting with nontradables, Lerner's symmetry theorem does not always hold. 
EIGURE ].A:

IMPORTABLES MARKET
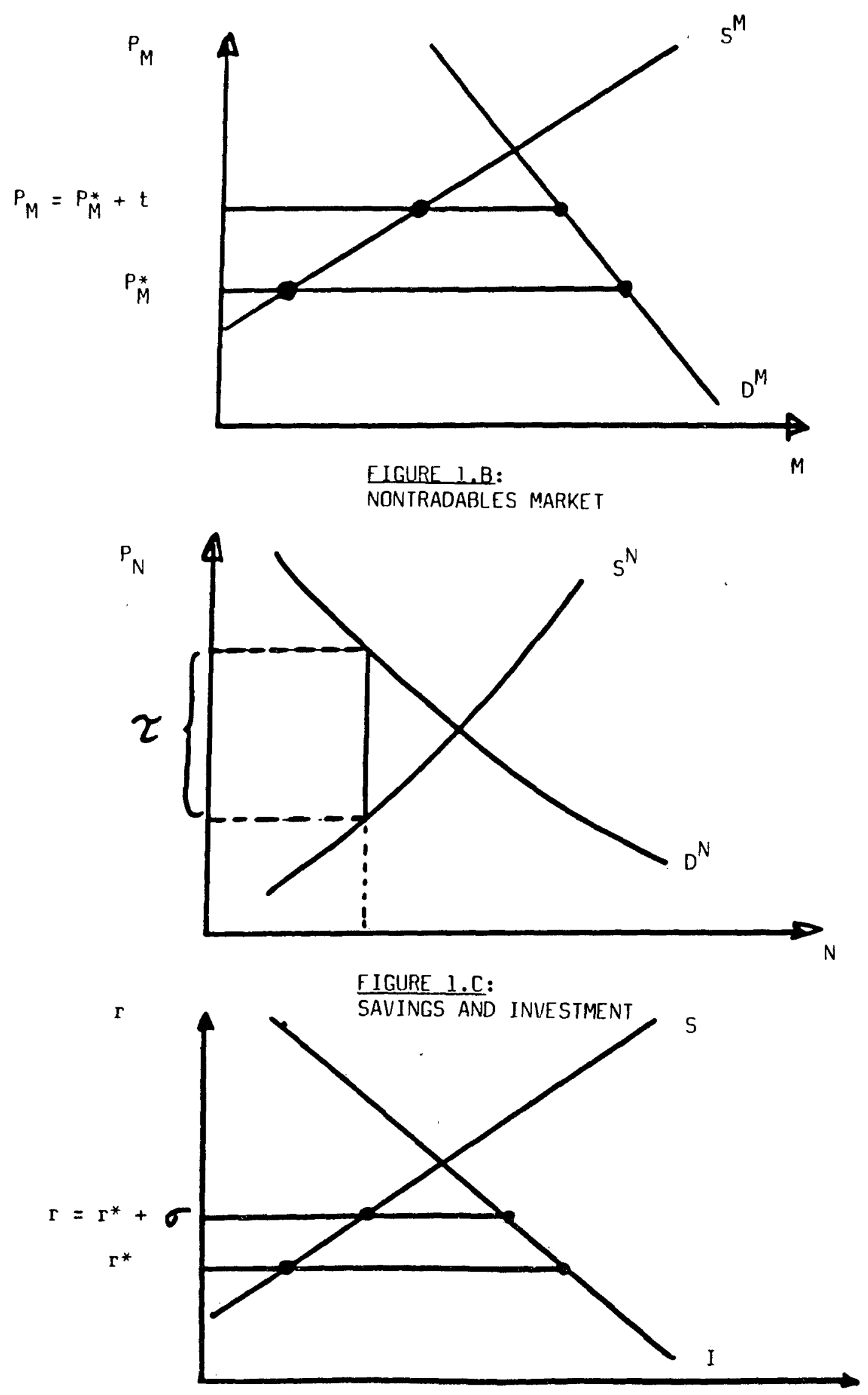

Savings,

Investment 
rate. Naturally, these markets are interconnected through the different general equilibrium links that are explained in Appendix A.

The figure capturing the labor market is somewhat more complex. The initial equilibrium in the labor market is represented in Figure 2, where the horizontal axis measures total labor available in the economy, the vertical axis depicts the wage rate in terms of exportables and the downward sloping schedules represent the value of marginal product of labor in the different sectors. Demand for labor by the tradable goods sectors ( $L_{T}$ ) is equal to the horizontal sum of the demand for labor by the exportables sector $\left(L_{X}\right)$, and the demand for labor by the importables sector $\left(L_{M}\right)$ (see Edwards, 1988a). Demand for labor by the nontradables sector is given by $L_{N}$. If there is a minimum wage rate equal to $\bar{w}$, unemployment will result. The amount of labor demanded by the nontradables sector is determined by point A and is equal to the distance $o_{N} L_{N}^{1}$; the amount of labor demanded by the exportables sector is given by the distance $O_{T}{ }_{X}^{1}$; and that demanded by the importables sector is equal to $\frac{1}{X} \frac{1}{T}$. Infitial unemployment is, then, given by the distance $\left(L_{\mathrm{T}}^{1} \mathrm{~L}_{\mathrm{N}}^{1}\right) \mathrm{P}^{14}$

This stylized economy, characterized by distortions in the four key markets forms the basis of our analysis. In the discussion of the welfare effects of alternative structural reforms we will make some additional simplifications, assuming, for instance, that some of these distortions do not apply to the case at hand. In that way it will be possible to

${ }^{14}$ This type of diagram has been used by a number of other authors to study the reaction of employment to number of policies. See, for example, Mussa (1974), Burda and Sachs (1987) and Edwards (1988a). Notice that the analysis can be extended to the case where the labor market distortion responds to factors other than minimum wages. One such case, which is discussed in Appendix B, occurs when there is labor market segmentation, and one sector (usually manufacturing) is subject to an above-market clearing wage while the rest of the economy is uncovered. 
FIGURE 2. LABOR MARKET EQUILIBRIUM

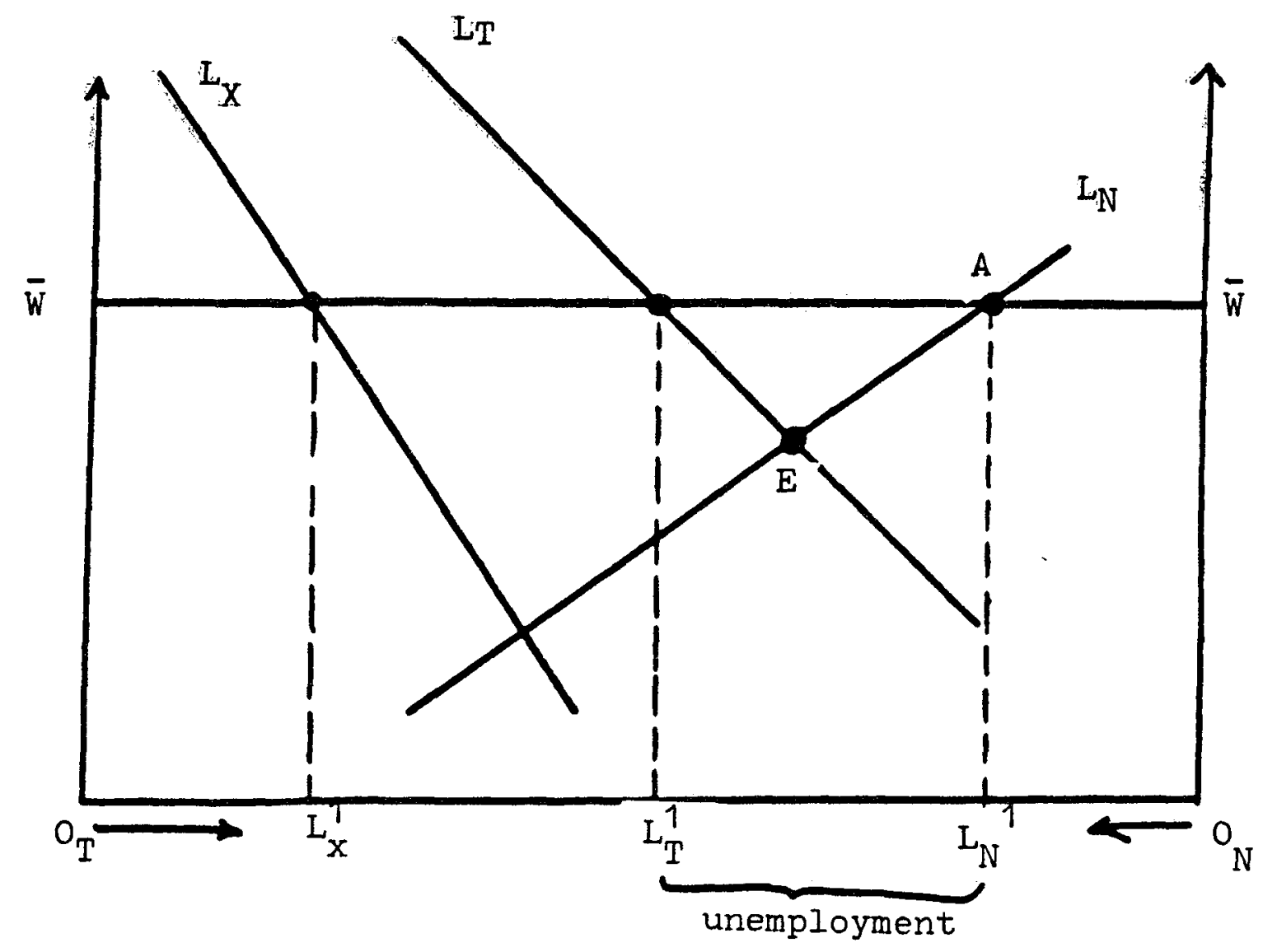


concentrate on specific effects without being side-tracked by too many complications. However, the way in which all the distortions interact among themselves will also be explained in some detail.

\subsection{The Interaction of Key Distortions}

When designing structural reforms it is cruclal to incorporate the interaction between the different distortions existing in the economy. Actually, not having taken these interactions into account has been at the

heart of the failures to sustain reforms in some of the LDCs. ${ }^{15}$ Unfortunately most of the traditional literature on the dynamics of structural reforms has ignored some of the most important and complicated interactions that can occur between different types of distortions. As will be illustrated in this subsection, these have to do with the way in which distortions to intertemporal trade interact with distortions to intratemporal exchange.

For instance, structural reforms that reduce import tariffs or taxes on nontradables, will affect savings through their impact on the relative price of future to present consumption, which we can call $\rho$. This relative price determines the allocation of total wealth across present and future consumption. An increase in $\rho$ makes future consumption more expensive and generates an intertemporal substitution towards the present and, consequently, a reduction in savings. This relative price can be written in the following way:

$$
\rho=\frac{(1+r)^{-1} \pi^{2}}{\pi^{1}}
$$

where I is the domestic real rate of interest, and is equal to the world

${ }^{15}$ See, for example, the discussion in Edwards and Cox-Edwards (1987). 
rate $r^{*}$ plus the tax on borrowing $\sigma$. Notice that $r$ is expressed in terms of the numeraire, which in our case are exports. $\pi^{2}$ is a price index of period 2 consumption and $\pi^{1}$ is a period 1 price index. $\pi^{1}$ and $\pi^{2}$, in turn, are functions of all domestic prices, including imports, in each perlod and, thus, also depend on the other markets' distortions. Denoting the domestic prices of imports and nontradables in period $i$ by $P_{M}^{i}$ and $P_{N}^{i}$, these price indexes can be written as positive functions of $P_{M}^{i}$ and $P_{N}^{i}$ : $\pi^{1}-\pi^{1}\left(\mathrm{P}_{\mathrm{M}}^{1}, \mathrm{P}_{\mathrm{N}}^{1}\right) ; \pi^{2}-\pi^{2}\left(\mathrm{P}_{\mathrm{M}}^{2}, \mathrm{P}_{\mathrm{N}}^{2}\right)$.

To illustrate how intratemporal changes in distortions also affect savings decisions, consider a case of an economy with capital controls (i.e., with a tax on borrowing) that embarks on an anticipated structural reform that will reduce both import tariffs and consumption taxes in period 2 . This means that both $P_{M}^{2}$ and $P_{N}^{2}$ will go down. As a result $\pi^{2}$ will decline and so will $\rho$. Future consumption will become relatively less expensive, and consumers will substitute away from current consumption. Savings, thus, will increase as a result of the anticipated reform. However, since due to the existence of the initial tax on borrowing $\sigma$, consumption in period 1 was initially too low, the increase in savings induced by the expected reduction in $\pi^{2}$ represents a negative welfare effect: in the presence of a tax on foreign borrowing an anticipated reduction in import tariffs and/or consumption taxes results in indirect welfare losses. In evaluating the reform as a whole we should then contrast this effect with the direct welfare gain resulting from the deregulation of the commodity markets in period 2 . A very important implication of the intertemporal substitution effect just described is that the expectations of future structural reforms many times will suffice for generating non-trivial welfare effects (see Edwards (1989c)). 
The type of interaction between inter-and intratemporal distortions will also be present in those reforms that imply a change in the extent of capital controls. For example, the relaxation of capital controls that will take place in the EEC in 1992, can be interpreted as a reduction in the tax on borrowing $\sigma$ and, thus, in the domestic real interest rate. As a result, the relative price $\rho$ will drop and present consumption will become less expensive. The resulting increase in perlod 1 expenditures will have a number of effects in all markets in that period, generating a number of indirect welfare effects (see Edwards and Ostry, 1989).

Generally speaking, changes in import tariffs and in taxes to nontradables will also have an impact on investment and through it they can also affect welfare. In the first place, if capital goods are imported, a reduction in tariffs will increase investment. On the other hand, structural reforms will change intratemporal relative prices, reducing the price of import competing, and possibly that of nontradables relative to that of exports. ${ }^{16}$ Depending on the factor intensities in the different sectors, this can result in an increase or decline in the economy's stock of capital, and thus in additional indirect welfare effects. In most of the discussion in Sections 4 and 5, however, we will ignore the effects on investment. This means that we will assume the current account as being absolutely determined by the amount of savings. A formal discussion of the effects of introducing investment into the analysis is done in Appendix A.

An important simplifying assumption adopted in this framework refers to the absence of adjustment costs. These types of frictions can be introduced

${ }^{16}$ Rigorously, the way in which the equilibrium price of nontradables will evolve following a structural reform cannot be determined a priori. See Appendix A. 
in a number of ways. Perhaps the easiest way of doing it is by assuming that in the short-run factors other than labor (i.e., capital and natural resources) are fixed in their sector of origin. These factors, however, can be reallocated slowly and in the long-run they do flow to their more productive activity. In this setting we will have a Ricardo-Viner representation in the short-run and a traditional Heckscher-Ohlin setting in the long run (see Mayer 1974, Mussa 1974, Neary 1978). The transition can be modelled in a number of ways, including the addition of a "moving industry", as in Mussa (1978), that uses factors during the reallocation process.

With this type of adjustment costs the short-run production possibilities frontier will be on the inside of the long-run frontier except at the initial equilibrium point, where they will be tangent (Mayer 1974). It is easy to show that if tariffs are the only distortion, in this setting it is still optimal to liberalize instantaneously: adjustment costs on their own do not constitute a reason for gradualism. However, adjustment costs combined with either price rigidities or uncertainty may, under some circumstances, dictate less than full and/or instantaneous liberalization. This is discussed in detail in subsection 3.4 .2 below. 17

\subsection{Extensions to the Basic Framework: Competition of Instruments and Credibility}

The framework presented above provides the more basic elements of the (general equilibrium) model we will use to analyze the welfare consequences of alternative structural reform programs. The model is deliberately simple, and concentrates on the more relevant features of the problem at

${ }^{17}$ Another useful simplification used in the text refers to the absence of intermediate inputs. However, as discussed in Appendix A, they can easily be introduced into our formal welfare framework for analyzing sequencing issues. 
hand. In this subsection we will expand the scope of our analysis of structural reforms by dealing briefly with two important related topics not captured directly by this framework: (a) competition of instruments; and

(b) the role of credibility.

\subsubsection{Competition of Instruments}

An important aspect of broad structural reforms is that many times significant policy tradeoffs will develop. The basic point is that the attainment of a particular target may require some variables (either exogenous or endogenous) to move in a particular direction while the attainment of other objectives will require those variables to move in the opposite direction. This problem is in part related to the policy assignment problem discussed by Tinbergen and Mundell in the 1960s. However, the current problem has a broader dimension stemming from intertemporal and credibility considerations.

Jeffrey Sachs $(1987,1988)$ has recently stressed in a forceful way the issue of competition of instruments within the context of the sequencing of structural reforms and stabilization programs. His main point is that countries such as Japan embarked on fundamental structural reforms geared towards liberalizing markets only after they had stabilized the economy. Based on this historical experience Sachs has argued that, analytically, when discussing issues related to sequencing one of the most important considerations has to do with the competition of instruments. ${ }^{18}$ Naturally, this problem is not only present when discussing the sequencing of stabilization and liberalization programs, but also when evaluating the appropriate order of a liberalization program.

${ }^{18}$ Sachs specifically points out that "the instruments of stabilization may well compete with the instruments of liberalization". 
In terms of our stylized model, real exchange rate behavior represents an important sphere where competition of instruments is reflected. In this model, the real exchange rate, or relative price of tradables to nontradables, plays a crucial role in the process of allocating resources. It can be shown that, under most plausible circumstances, a trade reform will result in (or "require") a real exchange rate depreciation, while a relaxation of capital controls will cause (require) a real appreciation. As pointed out in our review of the LDC literature, this has prompted a number of experts to argue against the simultaneous liberalization of the trade and capital accounts of the balance of payments.

A second important dimension related to the competition of instruments issue has to do with the effects of structural reforms on the sources used to finance government expenditures. In most analytical models, however, this issue has been set aside. ${ }^{19}$ The reason is that most models used to address the sequencing issue, including the one in Appendix $A$, have relied on the traditional assumption that tariff and tax revenues are returned to the public in a lump sum fashion. In reality, of course, this is not the case; governments use these revenues to finance their expenditures. In fact, when a government budget constraint is incorporated into the analysis, important policy dilemmas appear. For example, if government revenues are to be maintained constant, trade liberalization will require a hike in other tax sources, and, thus, will result in an amplification of other distortions.

This (simple) idea introduces some problems to the policy advice received from the $\mathrm{LDC}$-related literature. In fact, in that literature an important principle in terms of sequencing of structural reform is that a

${ }^{19}$ Surprisingly, perhaps, these effects have been ignored by most of the LDCs related literature. 
trade liberalization process, where tariff levels are reduced significantly, should only be undertaken once the fiscal sector has been reformed and other sources of revenue have replaced import tariffs. ${ }^{20}$ Notice, however, that in light of our previous discussion, this is by no means a trivial proposition. Indeed, even from a purely theoretical point of view it is not clear that reducing tariffs and increasing other taxes will be welfare improving. Moreover, at least at the theory level, it is not clear that welfare will increase if, as liberalization advocates have sometime proposed, consumption taxes are raised as tariffs are reduced.

This proposition can be shown formally using the following simple variant of the model described in Sections 3.1 and 3.2 and fully developed in Appendix A. Consider a small country that produces three goods: exportables, importables of type A, and importables of type B. Importables of type $A$ are subject to an (specific) import tariff $T$, while type-B importables are subject to a consumption tax $t$. World prices of $A$ are given and equal to $p^{*}$; world prices of $B$ are given and equal to $q^{*}$; and world prices of exportables are also given and taken as the numeraire. The government uses tariff and tax proceeds to finance its own consumption (G). For simplicity, and in order to focus on the discussion, we have abstracted from intertemporal issues as well as from those problems stemming from the existence of nontradable goods (see, however, Appendix A).

Using duality the equilibrium in this economy is fully described by equations (3)-(6), where $p$ and $q$ are domestic prices of imports of types $A$ and $B:^{21}$

${ }^{20}$ See, for example, Mckinnon (1984).

${ }^{21}$ On the use of duality theory in open economy issues see, for example, the textbook by Dixit and Norman (1980). 


$$
\begin{aligned}
& R\left(1, p, q^{*}\right)=E(1, p, q, W) \\
& G=\tau\left[E_{p}-R_{p}\right]+t E_{q} \\
& p=p^{*}+r \\
& q=q^{*}+t
\end{aligned}
$$

Equation (3) is the economy's budget constraint, where $R$ is the revenue function and $E$ the expenditure function; $W$ is the level of utility. Subindexes denote partial derivatives; that $1 s, \mathbb{R}_{p}$ is the derivative of the revenue function with respect to $p$. Notice that while $q$ is an argument of $E() \quad q^{*}$ is an argument of $R$, reflecting the fact that only consumption of $B$ is subject to a idistortion. $E_{P}$ and $E_{q}$ are the compensated demand functions for $A$ and $B$; $R_{p}$ is the supply function for A; $\left(E_{p}-\dot{R}_{p}\right)$ are imports of $A$. Equation (4) is the budget constraint of the government; its consumption $(G)$ is financed by tariff revenues $T\left[E_{p}\right.$ $\left.R_{p}\right]$, and by revenues from the consumption tax on good $B, t E_{q} \cdot$ Equations (5) and (6) establish the relation between world prices, the tariff, and the consumption tax. The presence of the budget constraint (4) is the main difference between this model and the one implicitly used in the traditional treatment of liberalization issues.

From equation (3) we obtain the welfare effects of unconstrained changes in the distortions, and $t$. From (4), on the other hand, we obtain the relation between $\tau$ and $t$ that yields a given government revenue. In fact, by totally differentiating (4) we can obtain the combination of $r$ and $t$ compatible with a constant level of government consumption. If, initially, the import tariff is below the maximum revenue level, a reduction of, will require an increase in $t$ in order to satisfy the budget constraint. That is, 


$$
\left.\left(\frac{d t}{d \tau}\right)\right|_{d G=0}<0 .
$$

We want to perform the following experiment: reduce import tariffs (i.e., liberalize trade) subject to the constraint that the government will still consume $G$ in real terms. We have then two equations ( 3 ) and (4), and two unknowns $W$ and $t$. Totally differentiating (3) and (4) we obtain (where, as before, subindexes refer to partial derivatives; and $C_{A}$ and $C_{B}$ are pure income effects for $A$ and $B$ ):

$$
\left(\begin{array}{ll}
\beta & \gamma \\
E_{q:} & E_{W}
\end{array}\right)\left(\begin{array}{l}
d t \\
d W
\end{array}\right)=\left(\begin{array}{c}
-\alpha d \tau \\
-\left(E_{p}-R_{p}\right] d \tau
\end{array}\right)
$$

where:

$\alpha-\left\{\left[E_{p}-R_{p}\right]+t E_{q p}+r\left(E_{p p}-R_{p p}\right)\right\}$

$\beta=\left\{r E_{p q}+t E_{q q}\right\}$

$\gamma=\left\{\tau C_{A}+t C_{B}\right) E_{W}$.

From (7) it is easy to show that, if $\tau$ is below the maximum revenue tariff, then:

$$
\left.\frac{d W}{d r}\right|_{d G=0} \gtrless 0 \text {. }
$$

This is, with a government budget constraint, it is not clear that a trade reform will increase welfare in the country in question. The reason, of course, has to do with the competition of instruments issue: a tariff reform "competes" with the goal of reducing distortions in other sectors. Moreover, if government expenditures are to be maintained constant, a reduction in tariffs will generally require an increase in other taxes, with the final welfare outcome being undetermined a priorl. 


\subsubsection{The Role of Credibility}

Most analyses on the sequencing of economic reform have based their conclusions on macroeconomic or welfare considerations. In the latter case the criterion used to choose a given course of action is simple: "sequencing $A$ is preferred to sequencing $B$, if social welfare under $A$ exceeds that obtained under B". Although in many ways, and especially in a theoretical sense, this is a useful and powerful criterion it does not address the important question of whether the government can equally precommit itself to carrying out both sequences. If this is not the case, then the two theoretical sequencings are not equally relevant from a practical point of view. This issue of precommitment is related to the important question of credibility of policy announcements which, in turn, is closely related to the question of what the public expects the government will do.

One of the most important developments of the last decade in the theory of economic policy refers to the formal incorporation of credibility effects Into its analytical framework. A key implication of this literature is that the absence of credibility is equivalent to a distortion; thus, we have to contemplate the possibility that the "incredibility" distortion will interact with the other distortions prevaling in the economy at the moment a structural reform takes place.

Traditional analyses of sequencing, including that developed in this paper, assume that the government is precommitted to whatever sequencing it announces. However, according to the modern theory of economic policy if the government runs into precommitment limitations we will have time consistency problems (see Kydland and Prescott 1977, and Calvo 1978). These types of problems emerge when all sources of taxation are distortionary and when future government actions affect the return of the assets held by the public. 
From an analytical point of view, to find out whether there are time consistency problems we should ask ourselves if in period 2 (the future) a benevolent government has incentives to renege on the policies it announced in period 1 (the present). If this is the case we say that the policy plan is time inconsistent. Moreover, if private agents form their expectations rationally they will understand that the government will indeed change (ex post) its policy, and will act accordingly, frustrating the reforms themselves.

It is easy to see that, generally speaking, some sequencing of structural reforms are credible, while others are indeed time inconsistent. For example, a reform based on the reduction of import tariffs is time consistent, since tariffs are always (in every period) welfare reducing. Consequently, once the government announces that it will liberalize trade, in period 2 it has no incentive to renege on its promises. This, however, will not be the case for reforms affecting the financial sector, such as the relaxation of capital controls, or straight financial liberalization programs. The reason, of course, is that in period 2 bond holdings, and savings and investment decisions will become predetermined. The government, then, can deviate from its announcement without imposing welfare costs. However, according to the new credibility literature, economic agents will know that the government has this incentive to renege on its promises and will take this information into account when making their optimal decisions. ${ }^{22}$ From a theoretical point of view, once time consistency issues are taken into account, the "adequate" results regarding the sequencing of reforms may differ from recommendations based on straightforward welfare considerations.

${ }^{22}$ On this see, for example, Calvo (1987, 1988). 
Researchers, however, have not yet been able to establish with precision how important these effects can be in real world situations. For this reason, the analysis of Section 4 will assume that the authorities do have the ability to precommit to any possible sequencing; thus, we will base our analysis and recommendations on intertemporal welfare considerations.

On the other hand it should be noticed that the recent literature $n$ credibility and sustainability of structural reforms has emphasized the $x$ of investment and of adjustment costs. ${ }^{23}$ Much of this research has incorporated the role of hysteresis into the analysis (Dixit 1987a,b). ${ }^{24}$ The main idea behind this approach is that in the presence of adjustment costs, exogenous shocks - - such as tariff liberalization, privatization or related policy measures - - will affect the (steady-state) equilibrium of the economy. In other words, in the presence of exit costs; barriers to entry, or other forms of adjustment costs, the behavior of the private sector can be affected by uncertainty, even when economic agents are risk neutral (Dixit (1987b)). This view has obvious implications for the evaluation of structural adjustment programs in the absence of full credibility: to the extent that the private sector attaches a positive probability to policy reversal, its behavior will greatly differ from what it would have been under policy certainty. More specifically, we can face situations where the lack of credibility -. reflected through a positive probability of a change in policy - - will prevent the private sector from investing in those sectors that become more profitable after the structural reform. Of course, to the extent that investment in the sectors with comparative advantage is not forthcoming

${ }^{23}$ See, for example, Dornbusch (1988) and Rodrik (1989).

${ }^{24}$ In the 1960 s Robert Mundell was an earlier proponent of using the term hysteresis in economic analysis. 
the success of the reform program as a whole will be in jeopardy. This is because the main objective of these polfcy packages is to reallocate resources towards more efficient activities. If this does not happen the reform as a whole would have failed. 25

Recently, Rodrik (1989) has developed a formal model to analyze how the interaction of credibility problems and adjustment costs affect the outcome of a structural reform program. ${ }^{26}$ In this model private investors have to decide whether to maintain their capital stock in the traditional (i.e., protected) sector or to move it to that sector favored by the structural reform (the "new" sector). Although the economic return in the "new" sector is higher than in the traditional sector, there is a probability $\pi$ of policy reversal. Given the existence of adjustment costs -. which in this model take the form of an exit and an entry cost .. once the policy reform is enacted, it is not obvious that it will pay to invest in the new sector. The reason, of course, is that if the policy is actually reversed those that have indeed reallocated capital will incur a cost. Rodrik computes the "required" return differential that, on the margin, will make investors indifferent between maintaining their capital in the traditional sector and moving it to the new sector. Not surprisingly, this required return differential will be higher the larger the adjustment costs and the larger the probability of reversal $(\pi)$. That is, the less "credible" the reform is, the lower

25 It is interesting to contrast the implications from hysteresis models to those of earlier work on adjustment costs such as the studies of Mayer (1974) and Mussa (1974, 1978) discussed above. In these earlier models adjustment costs took the form of fixed capital in the short run (1.e.. Ricardo-viner behavior). In that case, with slow reallocation of capital it was still optimal to eliminate tariffs instantaneously.

${ }^{26}$ Dornbusch (1988) has developed models on a similar framework for analyzing the role of credibility in stabilization programs. 
investment in the "new" sector will be.

A logical extension of this simple model is to endogenize the probability of reversal by making $\pi$ a function of how much investment takes place in the "new" sector: the larger the investment and the capital reallocation, the lower the probability of policy reversal and, thus, the higher the credibility of reform. Once this is done Rodrik shows that the system will exhibit two equilibria: a "good" one with a high degree of credibility, and a "bad" equilibrium with low credibility and low investment.

A direct, and not surprising, policy implication of Rodrik's model is that achieving credibility is a cruclal component of a successful structural adjustment. He correctly points out that policy unpredictability and uncertainty are highly detrimental for achieving high investment ratios and healthy growth rates. Rodrik then goes as far as stating that sustainability (or predictability) is in itself more important than the elimination of distortions and the liberalization of the economy. ${ }^{27}$ Interestingly enough, Rodrik's model with adjustment cost does not provide a case for gradual reforms. Quite on the contrary, in this model (as in that by Mussa (1984)) the government should act rapidly by providing a subsidy for investors to move into the "new" sector. In this way the apprehensions stemming from the lack of credibility will be compensated.

Nevertheless, bullding credibility is easier said than done. Despite some simple time consistency rules, at the present time a formal framework for analyzing credibility issues is still in their infancy. There is,

${ }^{27}$ In making this point Rodrik fails to address the important issue of the initial conditions. Within his framework we can think of economies that are initially so distorted that, even with a fairly high probability of reversal, it will pay to liberalize. Of course this point builds on the fact that the larger the initial distortions, the lower will be the rate of return to investment in the illiberal scenario. 
however, a growing agreement that maintaining a set of macroeconomic policies consistent with the liberalization reforms is a necessary condition for enhancing credibility (Edwards 1989d). ${ }^{28}$ In fact, we can now point to a number of recent historical episodes where macroeconomic mismanagement has led to a lack of credibility, which in turn has resulted in policy reversals and in failed structural adjustment programs. Perhaps the better known case is that of the liberal reforms in the Southern Cone in the late 1970s. At that time the authorities in Argentina, Chile and Uruguay embarked on ambitious programs to liberalize their economies by greatly reducing trade controls and relaxing the scope of domestic microeconomic distortions. 29 These policies were attempted at the same time as major stabilization programs aimed at reducing high triple-digit inflations were enacted. Although the macroeconomic packages implemented in these countries differed markedly, in all three cases a preannounced rate of devaluation (the socalled tablita) was adopted as a way to help reduce inflation. This devaluation scheme resulted, in the three nations, in steep real exchange rate overvaluations that cast serious doubts on the sustainability of the structural reforms. As the public realized that the real exchange rate overvaluation was inconsistent with a lowering of import tariffs it began to expect a reversal of the liberalization reforms. 30

${ }^{28}$ Strict political considerations are also important for determining the degree of credibility of a reform program. For example, new theoretical work combining economics with these type of considerations has suggested that the degree of efficiency of the taxation system (including import tariffs) is used by governments as a strategic variable. Countries with more stable political systems and less polarized constituencies will be more prone to introduce far-reaching structural reforms and will have greater credibility; see Cukierman, Edwards and Tabellini (1989).

${ }^{29}$ See Corbo and de Melo (1987).

${ }^{30}$ See Edwards (1985), Corbo and de Melo (1987). 
The way in which macroeconomic inconsistencies affected credibility was particularly important in Chile, the country where the trade reforms went the furthest. $^{31}$ starting in the late 1980s, as the degree of overvaluation became more and more unsustainable, expectations of devaluation experienced a significant increase. Of course, to the extent that this devaluation would Imply a real exchange rate realignment, the public expected that the real exchange rate would increase in the future. As the public became more convinced of the unsustainability of the external situation, the credibility of the overall liberalization strategy was reduced. Indeed in late 1981 an increasingly large number of people began to expect a collapse of the external sector policy, including a reversal of the tariff liberalization. As a way to cover themselves from these expected hikes in (domestic) import prices the private sector increased significantly its imports of durable goods. While in other countries of Latin America the loss of credibility in government poilicies resulted in outright capital flight, in Chile the drainage of international reserves took the form of huge jumps in the imports of automobiles and electronics. The loss of credibility in the government commitment for maintaining an open external sector was partially confirmed when in November of 1982 a number of imports became subject to an import surcharge that fluctuated from 4 to 28 percent. Later in June of 1983 import tariffs were raised to a uniform 20 percent, and in September of 1984 they were further increased to 35 percent. 32

$31_{\text {Between }} 1975$ and 1979 Chile eliminated all quantitative restrictions and reduced tariffs from an average of 1008 to a flat $10 \%$ level.

${ }^{32}$ On the details of this partial reversal see Edwards and Cox-Edwards (1987). It should be noted, however, that in 1986 tariffs were again reduced to 208 . 
The lack of credibility also played an important role in the failure of the Argentinian liberalization attempt under Minister Martinez de Hoz. In this case the private sector assigned a very high probability to the reversal of the tariff reduction policies and, thus, borrowed heavily abroad in order to finance what they considered to be temporary losses stemming from the (perceived) temporary liberalization. As Carlos Rodriguez (1983, p. 28) has put it: "As a consequence of the lack of credibility many firms - - which would have disappeared due to the tariff reductions - - decided to go into debt in order to keep operating while waiting for a change in economic strategy". Of course, given the macroeconomic inconsistencies, the agents' expectations proved to be correct and both the "tablita" and the structural adjustment program had to be abandoned in early 1981 (see Calvo 1983, 1986, and Corbo and de Melo 1987). 


\section{Welfare Effects of Structural Reforms: Sone Illustrations Based on OECD-Type Economies}

The purpose of this section is to illustrate the working of our framework, and to highlight, with two specific examples, the different channels through which structural reforms will affect social welfare. We do this by considering two reform measures in hypothetical economies that, in some way, resemble two types of OECD countries. Our first example is a micro-oriented reform aimed at reducing import tariffs in an economy with labor market distortions and service sector regulations. Our second example deals with the relaxation of capital controls in an economy that also has labor market distortions. These examples allow us to better understand the dynamics of reforms in an intertemporal general equilibrium setting, and thus provide important information for the analysis of sequencing strategies of Section 5. The discussion that follows is supplemented by a formal analysis of the welfare consequences of these two policies presented in Appendix A.

\subsection{The Dynamics of Structural Reforms of Product Markets}

In this subsection we discuss how structural reforms geared at reducing distortions in the products markets affect social welfare in a highly simplified fictitious economy that resembles the most advanced OECD economies. This fictitious economy, which we will call a G-type economy is characterized by extensive regulation of labor and some product markets, freedom of capital movements, relatively few but specific barriers to trade, and a floating exchange rate. The reforms are focused on reducing the extent of regulations in specific sectors (some of them services), including trade barriers. Another goal of the reforms is to reduce the extent of labor market distortions. In terms of our stylized model of Section 3 this 
means that only 3 of the 4 markets considered are distorted; since there are no capital controls, intertemporal decisions are not assumed to be affected. Using the framework discussed above, and fully developed in Appendix A, we first analyze the case of tariff reduction. This exercise provides a clear flavor of the dynamics of reform. We next discuss the effects of a deregulation of a service sector.

In order to organize the discussion it is useful to distinguish between three different types of welfare effects that will be generated by structural reforms:

(1) Direct welfare effects that accrue in the reformed market. These basically correspond to efficiency gains and are the conventional Harberger-type triangles. Depending on when the reform takes place (period 1 or period 2) these direct effect will be present in one or more periods.

(2) Indirect intratemporal welfare effects. These arise from the interaction of two or more distortions in the same period, and take place when the reform in one market spills to other distorted market. In terms of traditional welfare economics, these indirect effects correspond to welfare "rectangles" (see Harberger 1971a).

(3) Indirect intertemporal effects. These are due to the dynamic intertemporal nature of our model. These kinds of effects will be present when a reform in, say, period 1, alters the equilibrium in distorted markets in period 2.

\subsubsection{Anticipated Tariff Reductions}

We first analyze the welfare consequences of a structural reform that consists of a reduction in import tariffs. In order to highlight the role of intertemporal channels and of expectations we will analyze the case of a 
preannounced (and fully anticipated) reform that will take place in the future (second period). In our analysis we will focus on the 3 types of effects described above.

i) Direct Welfare Effects

Figure 3.A captures the direct welfare effects of the anticipated tariff reform. They correspond to the traditional textbook triangles A and $B$. Since these efficiency gains take place in period 2, in our computation of the total welfare consequences of this reform we have to discount them back to the present. Consequently the direct welfare effects (DWE) are (approximately) given by:

$$
\begin{aligned}
\text { DWE } & =\delta *[\text { gain in consumer surplus in period } 2+ \\
& + \text { gain in producer surplus in period } 2],
\end{aligned}
$$

where $\delta *$ is the appropriate discount factor.

\section{ii) Intratemporal Indirect Effects}

We now deal with the interaction between the reduced distortion in the current account in period 2 and the other two distorted markets in that perlod. The lower domestic price of importables will generate a series of cross demand effects in other sectors. If we assume that importables and nontradables are substitutes, the demand curve for the former will shift backwards generating an indirect welfare loss. The magnitude of this loss is captured by the shaded area in Figure 3.B. The reason for this indirect welfare loss is that "too little" was already being consumed of $N$ in period 2; the tariff reduction in the $M$ sector has thus amplified a preexisting distortion. Naturally, if instead of assuming substitutability we assime complementarity in consumption between $N$ and $M$, instead of a welfare loss we would have a welfare gain. 
FIGURE 3.A

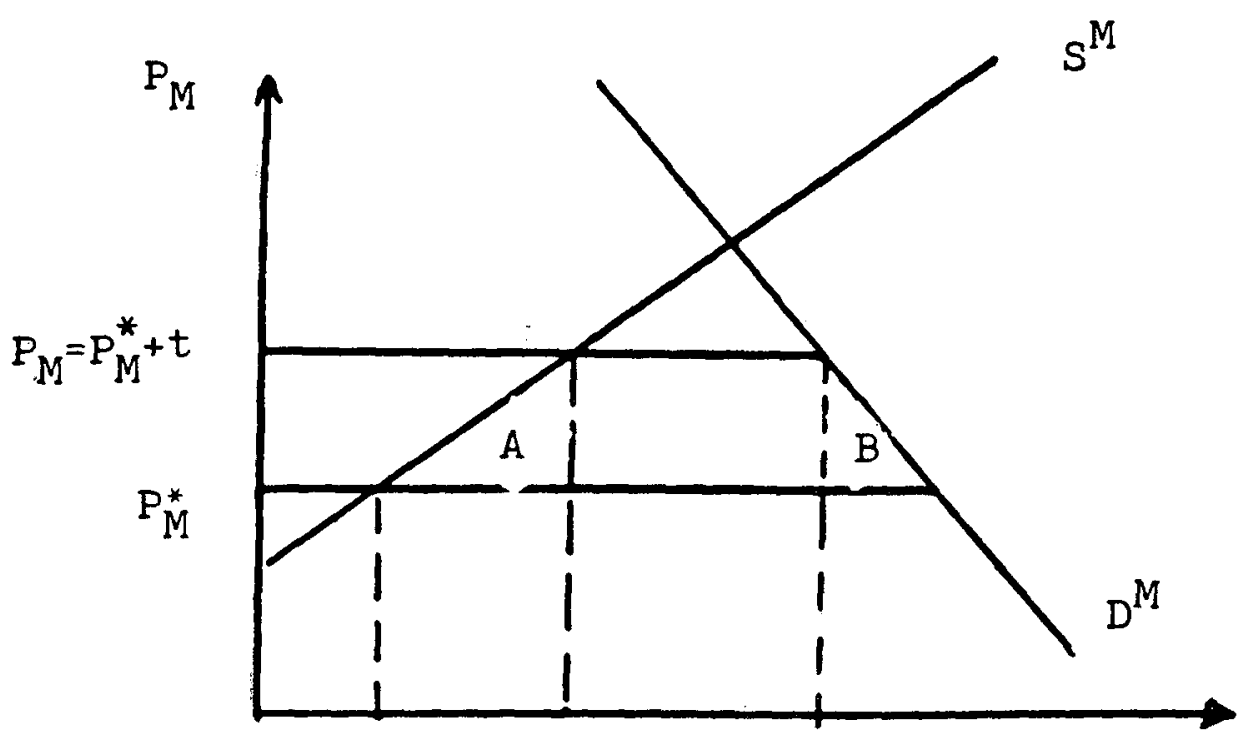

FIGURE 3. B

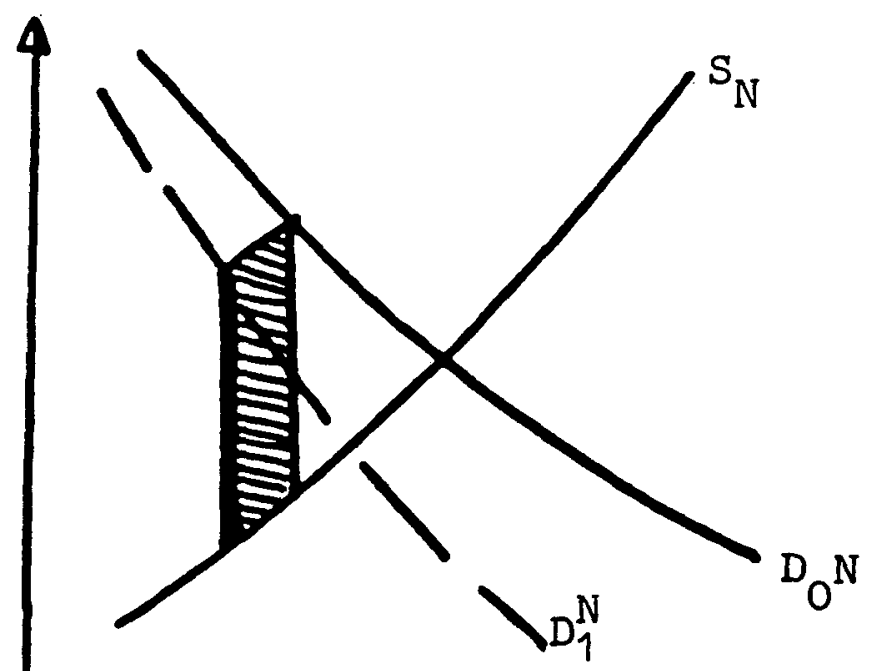


This indirect intratemporal effect is (approximately) given by: ${ }^{33}$

$$
\begin{aligned}
& \text { Indirect Effect } 1 \text { - tax on nontradables } \times \\
& \text { [change in equilibrium consumption of } N \text { ] }
\end{aligned}
$$

Notice from Figure 3.B that an important effect of the trade reform is that, under our specific assumptions, it results in a reduction in both the producer and consumer prices of nontradables $\left(q^{2}\right.$ and $\left.\rho^{2}\right)$. As will become clear later, these changes in the relative price of nontradables (or real exchange rate) play an important role in evaluating the welfare consequences of alternative sequencings of liberalization.

Let us now focus on the interaction between the trade and labor market distortions. In order to organize the analysis we will proceed by steps, assuming first that other factors (capital and natural resources) are specific to their sector of origin. ${ }^{34}$ we then will discuss what happens when these factors are allowed to reallocate across sectors. The question we want to answer is what will be the effect of the tariff reform on aggregate employment in period 2. Since due to the pre-existing distortion employment is too low any reform in other sectors that generates an increase (decline) in aggregate employment will generate an indirect welfare gain (loss).

The tariff reduction itself will result in a lower domestic price of importables and will, thus, generate a downward shift of the value of

${ }^{33}$ This, of course, is a partial equilibrium approximation. In fact, rigorously it is not completely correct to refer to this effect as being purely intratemporal. As is shown in Appendix A, what matters is the change in the price of $N$ in period 2, as a result of the anticipated tariff reduction. The change in this price is, in turn, the result of combined inter- and intratemporal forces. What we are implicitly assuming here is that the intratemporal forces dominate. For a detailed discussion see Edwards $(1989 a, c)$. For the general equilibrium expression see Appendix A.

${ }^{34}$ That is, we will proceed as if we were dealing with a Ricardo-Viner model. 
marginal product schedule for $M$. In Figure 3.C this is captured by the leftward shift of the $\mathrm{L}_{\mathrm{T}}$ curve to $\mathrm{L}_{\mathrm{T}}^{1}$. On the nontradables side something similar will happen. The reason is that, as shown in Figure 3.B, the reduction in the tariff will result in a lower (product) price for nontradables. This, in turn will result in a reduction in the demand for labor for use in the $\mathrm{N}$ sector. This effect is reflected in Figure 3.C by the downward shift of schedule $\mathrm{L}_{\mathrm{N}}$ to $\mathrm{L}_{\mathrm{N}}^{1}$. As can be seen from Figure 3.C, under the assumption of no reallocation of other factors, these two effects amount to an increase in the level of unemployment in this economy. The reason, of course, is that the existence of a rigid wage in real terms will preclude the full adjustment of the labor market.

It should be noted, however, that this is the final outcome under the rather restrictive assumption of a Ricardo-Viner model. If, alternatively, It is assumed, that factors are free to move across sectors, we will observe capital and natural resources moving out of the sector(s) with reduced "competitiveness" and into that (those) sector(s) where competitiveness has increased.

As this process of reallocation take place, our labor demand schedules in Figure 3.C will shift around: upward in those sectors that experience an inflow of factors, and downward in those sectors that release factors. Naturally, the final equilibrium will depend on the magnitude of these shifts. These, in turn will depend on the relative factor intensities of the three sectors and, thus, on the nature of the Rybczynski effects. It turns out that in our ( $3 \times 3)$ model it is not trivial to determine the signs of these Rybczynski terms (In Appendix A we provide a discussion of this problem). Here, however, and in order to simplify the discussion, we will assume that the fimport competing sector has the highest capital labor ratio 
FIGURE 3.C. LABOR MARKET ADJUSTMENT

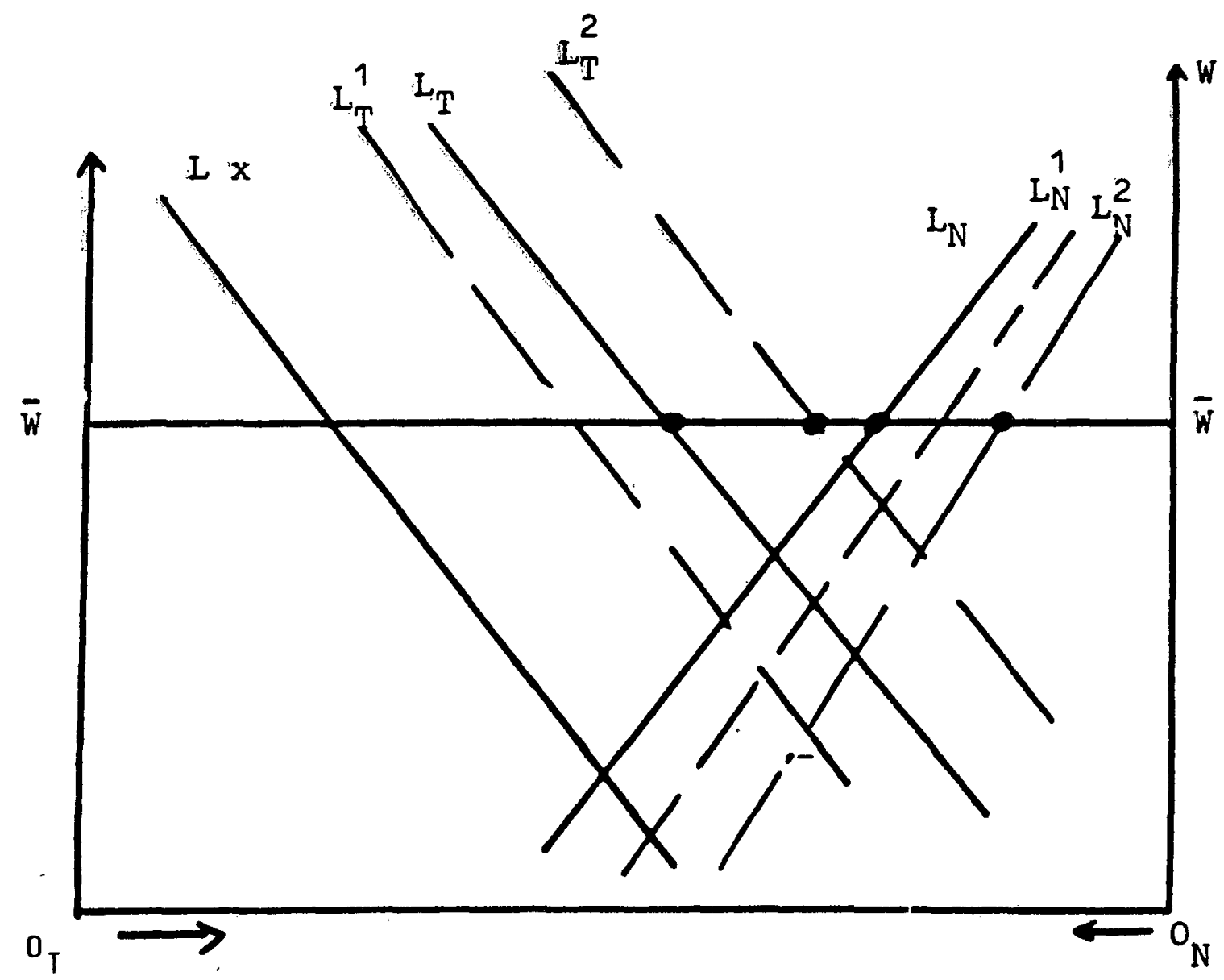


and that exportables have the highest natural resources labor ratio.

Nontradables, on the other hand, have the lowest of both intensities. 35 Under these assumptions, the effect of the tariff reform will be that the $\mathrm{L}_{\mathrm{N}}$ curve will shift further back to $\mathrm{I}_{\mathrm{N}}^{2}$, while the $\mathrm{L}_{\mathrm{T}}$ curve will shift up to $\mathrm{L}_{\mathrm{T}}^{2}$. Thus, as can be seen in the diagram, the tariff reform will provoke a decline in unemployment in period 2. This, of course, means that the tariff reform has generated a positive intratemporal indirect effect through the labor market. This effect can be captured by:

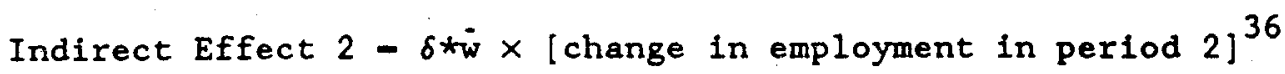

\section{1) Intertemporal Indirect Effects}

The results sketched above are quite standard and can be obtained from raditional trade models. However, once intertemporal links are introduced a number of additional possibilities emerge. In particular, as explained in Section 3.3 above, an anticipated tariff reduction will result in an increase of the consumption rate of interest and in substitution away from present consumption and into future consumption. This change in the intertemporal profile of consumption will not only affect the economy in the period when the reform takes place (period 2 in our case), but also in the other periods.

In the case of a G-type economy, we will have three intertemporal indirect effects; one affecting each distorted market in period 1 . We will first have an indirect effect on the amount imported in period 1 . The expected reduction in tariffs in period 2 will induce (intertemporal)

${ }^{35}$ Denoting capital, labor and resources by $K, L$, and $R$, we are assuming that $(R / L)_{X}>(R / L)_{N}$ and that $(K / L)_{M}>(K / L)_{X}>(K / L)_{N}$.

${ }^{36}$ The reason why in this expression we have the rigid (minimum) wage $\dot{w}$ is that we have assumed an inelastic labor supply. If, instead, we assume an upward sloping supply of labor, the expression would have the difference between the minimum wage and the supply price of labor. 
substitution away from imports in period 1. Since due to the tariff the economy was already importing too little in that period, this substitution will represent a negative effect which will be given by: ${ }^{37}$

\section{IIEI - tariff in period $1 \times$}

[change in period 1 imports induced by expected reform]

The second type of indirect effect is related to the behavior of the nontradables market in period 1 . Since part of the lower expenditure in period 1 will come from lower consumption of nontradables this market will also be affected, and the sign of this effect will also be negative. The reason, once again, is that the anticipated reform will induce a reduction in the level of activity in a market that, due to existing distortions, was already producing too little. ${ }^{38}$ This indirect effect will be given (approximately) by:

\section{IIE2 - Tax on Nontradables $x$ \\ [Induced Change in Consumption of $N$ in period 1]}

The third effect is, as before, related to the labor market. Now, however, all the action will come from the change in the price of nontradables in period 1 . Since the anticipated reform has resulted in a reduction in the price of nontradables in period 1, the direct effect will be that the demand schedule for labor in $N$ will shift downward. Furthermore, under our assumptions of factor intensities the final effect will also be a reduction in period 1 employment. This, of course, will impact negatively

${ }^{37}$ In terms of notation IIEi stands for "Intertemporal Indirect Effect number $i "$.

${ }^{38}$ Naturally, if instead of a tax we assume that the nontradables sector is subject to a subsidy, the indirect effect would be positive. 
on welfare. Formally, the (approximate) magnitude of this effect will be given by:

$$
\text { IIE3 }-\bar{w} \times \text { [Induced Change in Employment in Period 1] }
$$

The total welfare effect of this anticipated tariff reduction will, then, be given, by the sum of the discounted value of the direct efficiency gain (DWE), plus the discounted sum of the two intratemporal indirect welfare effects, plus the sum of the three intertemporal indirect welfare effects. Naturally, in this exercise there is no guarantee that the total welfare implication of this (anticipated) structural reform will be positive. In fact, it may very well be negative, indicating that this partial reform is not worthwhlle undertaking. This, of course, is not surprising. It is nothing more than an application of the generalized theory of the second best.

It should be noticed that the approach taken here .. and especially the organization of the effects into three different categories .. can be applied to advantage to any combination of reforms and thus can, in principle, be used to evaluate any sequencing or speed of structural reform. Moreover, at this level of analysis -. diagrammatic and partial equilibrium -- there is no problem in expanding the horizon of the discussion to three or more periods. 39

\subsubsection{Deregulation of the Nontradables Sector}

The dynamics of the welfare effects of a reform aimed at reducing taxes in the services sector in a G-type economy is perfectly analogous to that of the imports sector which we discussed above. For this reason there is no

${ }^{39}$ However, as pointed out in Appendix $A$, the extension of the formal general equilibrium framework to anything more than two periods makes things rather cumbersome. 
need to repeat here all the mechanics involved in such an exercise. There is, however, one important difference between these two cases which is worth emphasizing. While changes in import tariffs will affect, via a number of channels, the equilibrium prices of nontradables, the converse is not true. That is, reforms that alter taxes, and thus prices in the nontradables (services) sectors, will not change the domestic price of importables or exportables. The reason for this is straightforward and is related to our small country assumption. This means, then, that when the reform takes place in the nontradables sector there will be one channel of transmission less than when it occurs in the tradables sector.

\subsection{Relaxing Capital Controls}

Our previous discussion has completely ignored the role of capital controls. The reason for this is that we have focused on what we have called a G-type economy, where impediments to capital movements have no practical relevance. Within the OECD, however, there is another group of countries for which slightly different problems than those faced by the $G$ countries, are important. These economies, which we can call NZ-type economies, are characterized by micro and macro structural problems, balance of payments difficulties, large stock of foreign debt, controls on capital movements, and regulations to the financial market. In this prototype economy the focus of reforms is broader than in G-type countries, and also includes the relaxation of capital controls and a more generalized trade liberalization. There is also a need to attain macroeconomic equilibrium. However, we will relegate the discussion on the relation between macroeconomic stabilization and structural reforms to Section 5 and we will briefly analyze here the important issue of the welfare effects of relaxing of capital controls. In order to focus the discussion we will abstract from 
distortions to the tradables and nontradables sectors. We will consider the case of an economy that limits capital mobility via a tax on borrowing and faces labor market distortions of the form of real wage rigidity. Furthermore, in order to focus even more on the analysis, we will assume that the wage rigidity (or the minimum wage) is restricted to period 1 only. Naturally, given these assumptions, we will not have all three types of welfare effects discussed in the previous section. In fact, we will only have a direct effect stemming from the relaxation of the capital controls, and an intertemporal indirect effect related to the interaction between the capital controls and the minimum wage in period 1.

In its simplest form our question can be posed as follows: What will be the welfare effects of decreasing the extent of capital controls in an economy with labor market distortions in period 1 ?

The reduction of the tax on foreign borrowing will tilt the intertemporal allocation of expenditure towards the present. A proportion of the increased expenditure in period 1 will fall on nontradables. This will result in an increase in the price of $N$ in period 1 (a real appreciation in period 1) and, thus, will generate an increase in the demand for labor in the nontradables sector in that period. Since employment in that period was initially "too low", the reduction of the tax on foreign borrowing will tend to reduce that distortion, generating a positive welfare effect. As before, however, the story does not end here, since the increase in the relative price of nontradables will trigger a reallocation of the flexible-price factors from the $X$ and $M$ sectors to the $N$ sector. Depending on the relative labor intensities across sectors this reallocation effect may result in a net reduction or a net increase in aggregate employment. If we assume that the tradables sectors (exportables and importables) 
are as a group, less labor intensive than the $N$ sector, the factor reallocation effect will work in the same direction as the real exchange rate effect and, as a consequence of the relaxation of capital controls, total unemployment in period 1 will decline. As a result, in this case the net effect of the reduction of taxes on foreign borrowing has been welfare increasing. More generally, what this means is that the existence of unemployment and (real) wage rate rigidity in period 1 provides no justification for capital controls.

In fact this analysis has a falrly startling corollary: in an economy characterized by (a) a minimum wage in terms of exportables in period 1 only, (b) no initial distortions on capital flows, and (c) nontradables being more labor intensive than tradables as a group, a small subsidy on foreign borrowing will be welfare-improving. The intuition is straightforward: the minimum wage has resulted in a lower than optimal level of employment in period 1 . The subsidy on foreign borrowing will tilt expenditure towards period 1; part of this extre expenditure will fall on nontradables, driving their price up and thus generating an increase in employment in that period. Moreover, since we assume no initial tax (or subsidy) on borrowing, the small subsidy will not generate a first order welfare effect. The effect of this small subsidy on foreign borrowing on the labor market is captured in Figure 4, where the shift of $L_{N}$ to $L_{N}^{1}$ is the result of the real exchange rate effect of a higher $\delta$, and the shifts of $\mathrm{L}_{\mathrm{N}}^{1}$ to $\mathrm{L}_{\mathrm{N}}^{2}$ and of $\mathrm{L}_{\mathrm{T}}$ to $\mathrm{L}_{\mathrm{T}}^{1}$ are the consequences of the reallocation of the cooperative factors. Given our assumptions regarding labor intensities, the net effect on employment of this reallocation is positive. 40

${ }^{40}$ Edwards and Ostry (1989) provide a detailed discussion in a similar context. See also Appendix A. 
FIGURE 4. LABOR MARKET ADJUSTMENT

TO A SMALL SUBSIDY TO

FORE IGN BORROWING

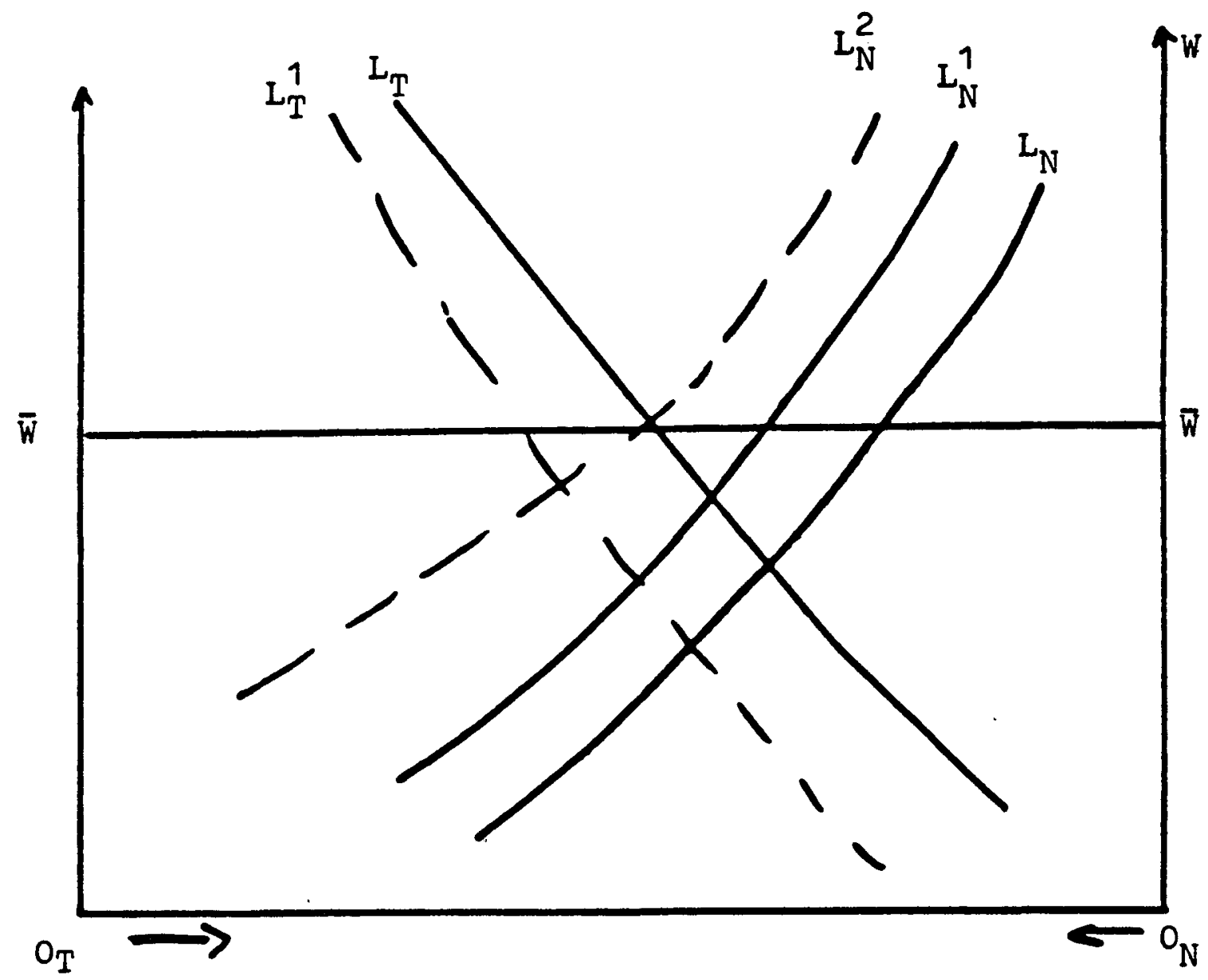


This discussion, then, provides additional elements for a general application of our framework to the question of the consequences of alternative sequencings. Notice that, as before, one of the key determinants of the direction of the welfare changes was the assumption regarding factor intensities of the different sectors.

\subsection{Synthesis}

The analysis presented above has shown the way in which different distortions interact in our intertemporal general equilibrium framework. The classification of these effects into three distinctive categories - direct effect, intratemporal indirect welfare effects, and intertemporal welfare effects - provides a useful organizing framework for analyzing, at least qualitatively, the welfare consequences of alternative structural reform packages.

In terms of possible empirical applications of this framework, the examples presented above indicate that data on a number of key parameters would be required before being able to compute any magnitudes in terms of welfare changes. First, it is necessary to have data on intertemporal substitution elastifcities. These are required to deal with all our intertemporal effects. Second, our examples suggest that, both in $G$ and NZ type economies, one of the most important determinants of the welfare effects refer to the induced changes in employment. As argued above, in order to have a clear idea of the direction these effects will take, it is first necessary to know the relative factor intensities of the different sectors involved. In addition, information on the elasticities of labor demand would be required. Moreover, once the framework is extended to allow for an upward sloping supply of labor, knowledge about the elasticity of this supply would also be needed. 
Another important principle that emerges from the examples presented above is that in a sequential reform, as more and more markets are freed of distortions, successive reforms will generate fewer and fewer intratemporal indirect effects. This simple principle provides an argument for placing up front in the reform sequence the liberalization of those markets with substantial positive indirect intratemporal effects. Alternatively this principle states that, with other things given, the reform of those markets with large negative intratemporal indirect effects should take place towards the end of a reform sequence.

In terms of our examples, the above considerations suggest that, under our assumptions of substitutability and relative factor intensities, it would be more prudent to postpone the liberalization of the trade sector until the services markets have already been reformed. ${ }^{41}$ Likewise, our previous examples suggest that it is prudent to relax capital controls before eliminating labor market distortions. It should be stressed that in the above assertions we have deliberately used the word prudent when referring to the more appropriate sequencing. By using this word we want to make clear that we are not stating any theorems, but rather organizing and summarizing what our analysis suggests would be the more plausible outcome for most countries if a serious numerical exercise on the matter is undertaken. Notice that in the preceding analysis we have assumed that the intertemporal effects of specific reforms are particularly important for evaluating their welfare consequences. However, in a number of cases .. and in particular in the case of future reforms .- these intertemporal effects will only take

${ }^{41}$ It is very important to stress that this and the following statements assume that a simultaneous reform that eliminates all distortions is not feasible. As is discussed below in this model this simultaneous sequence constitutes the first best solution. 
place if the private sector indeed expects the reforms to take place in the future. If, however, the authorities do not announce the future reforms, or if the announcements lack credibility, these intertemporal effects will either be absent, or will be substantlally weakened. This consideration. then, suggests that when deciding on the sequencing of reform the role of intertemporal effects stemming from future reforms should be looked upon with some skepticism, and that the credibility issue, and especially the precommitment aspect discussed in Section 3, should be considered very seriously. In the actual case of the EEC nations, however, the fact that (some) reforms are part of an international agreement does indeed provide at least a partial precommitment technology. 
5. General Features of Alternative Sequencing Strategies, Policy Implications and Recommendations for Future Work

The purpose of this section is threefold. It first aims at putting the previous analysis in perspective and providing some general policy recommendations regarding reform sequencing. Second, we deal with the important question of the interaction between structural reform policies and macro-stabilization programs. In doing this we discuss the recent World Bank experience with trade liberalization in countries suffering from macroeconomic disequilibrium. Finally, the section ends with a discussion of how to proceed with this type of research. In particular we focus on possible ways of instrumentalizing and empirically applying this framework.

\subsection{Broad Front vs. Sequential Concentrated Approaches}

In most $O E C D$ countries welfare considerations provide the relevant criterion for deciding on the appropriate sequencing of reform. ${ }^{42}$ within the context of our intertemporal equilibrium framework, and at a very general level, the answer to the sequencing problem is rather simple -. or even trivial. The sequence that results in the highest social welfare $V$ should be adopted. That is, if we consider four possible sequences A, B, C and $D$ this principle states that sequence $A$ is preferred to all the others if:

$$
\begin{aligned}
& \mathrm{V}(\mathrm{A})>\mathrm{V}(\mathrm{B}) ; \\
& \mathrm{V}(\mathrm{A})>\mathrm{V}(\mathrm{C}) ; \text { and } \\
& \mathrm{V}(\mathrm{A})>\mathrm{V}(\mathrm{D}) .
\end{aligned}
$$

${ }^{42}$ An exception to this are those countries that resemble what we have called an NZ-economy. In this case, in addition to welfare considerations, macroeconomic conditions should also be taken into account. See subsection 5.3 on how issues concerning micro reforms and macro adjustment can be combined. 
Moreover, speaking at a strictly theoretical level, within the context of our model -. or of most general equilibrium fully optimizing models -. the preferred sequence will be one where all markets are reformed simultaneously. The reason for this rather impractical result is that in this model (as in most models used for similar analyses) we assume that the existing distortions are government-imposed rather than structurally inherent to the country. ${ }^{43}$ of course this answer .. reform all markets simultaneously - is not only not realistic, but also trivial. For this reason, in order to give some structure to our sequencing question it is necessary to first assume that, for one reason or another, not all distortions can be eliminated simultaneously. This, in fact, has been the way in which the LDCs literature on the subject has usually proceeded (see Edwards 1984).

In the case of most of the OECD nations the most reasonable assumption seems to be that labor market distortions are the most difficult to eliminate. Thus we can restate our sequencing question within a second best context, asking what is the optimal sequence for reforming the nontradables (or services) and importables sectors under the assumption that the labor market will be reformed last. Alternatively, we can pose the question as follows: are there any welfare reasons that suggest that in an economy with labor market distortions it is optimal not to implement all other reforms simultaneously? That is, are there welfare reasons to think that a

${ }^{43}$ In rigor, not even in the case of structural market failure can we escape the advice of taking all the measures -. in this case reforms-cumintervention to correct the failure -. simultaneously. This, of course, assumes away the hysteresis case discussed in Section 3.4.2. 
sequential concentrated approach is preferable to a broad front approach? ${ }^{44}$ Naturally, the assumption that the labor market will be the last to be deregulated already suggests that the answer to this question will be closely related to whether the reforms increase or decrease the level of employment in the economy.

As was suggested above, and as it is shown formally in Appendix A, given our assumptions about intertemporal substitutability and relative factor intensities, there is a presumption that if all markets cannot be Iiberalized simultaneously, the reforms of the domestic (nontradables) sector should precede that of the importables sector. But at this stage this is nothing more than a presumption. In order to have a more clear and definitive answer, it is necessary to push our framework further and to move closer to empirical applications. That is the subject of Section 5.4 below.

\subsection{Abrupt or Gradual Reforms?}

For many years the issue of gradualism vs. abrupt reforms was discussed in an ad-hoc manner, without relying on a formal framework rooted in optimizing intertemporal models. ${ }^{45}$ The model developed in this paper, however, provides the minimal rigorous framework to address this speed issue. From a welfare point of view the factors that should be taken into account in analyzing the optimal speed problem are virtually the same to those

${ }^{44}$ It is very important to notice that this framework is general enough as to allow us to evaluate any combination of reform sequencing. For instance the sequencing of liberalization of the capital and current account which has occupied much of the attention of the policy literature in the LDCs. Since in our case we have assumed that the labor market remains distorted, an interesting question is what is the "shadow price" of this remaining distortion when other sectors are liberalized. If our model is parameterized and simulated an exact answer to this important question can be found.

${ }^{45}$ This applies especially to the discussions on the appropriate speed of stabilization in Latin America. 
considered in the optimal sequencing discussion.

In the absence of market failures or distortions, the answer to the optimal speed question is again rather trivial. All markets should be reformed now. For this reason this question is interesting only if criteria other than welfare are considered or if we assume that for political or other reasons, not all markets can be reformed simultaneously.

Possibly the simplest way to rigorously approach this question is to follow the methodology proposed by Edwards and van Wijnbergen $(1986,1987 \mathrm{~b})$. In these papers the authors bufld a two-perfod model of a fully optimizing economy with tradable goods only and assume that a tax on foreign borrowing for investment purposes is maintained throughout. They then ask what is the optimal speed of trade reform. Formally they analyze this question in the following way: they assume that an abrupt liberalization implies zero tariffs both in periods 1 and 2, while gradual reform implies a positive tariff in period 1 and a zero tariff in period 2. Given this setting they then ask what is the optimal tariff in period 1 . They find that indeed a positive (but not very high) tariff in period 1 with no tariff in period 2 is optimal in a second best sense. This, of course, supports the idea that with an intertemporal distortion of the type considered by them it is optimal to implement a gradual reform. Naturally, this type of analysis can be easily undertaken with our model. The specific results will depend on the particular assumptions made about the non-removable distortion.

\subsection{Macro vs, Micro Reforms: Does the Order Matter?}

Up to now our discussion has centered exclusively on the different welfare ramifications of structural reform, ignoring macroeconomic considerations. However, as mentioned before, for a small group of OECD 
countries the question of the sequencing between macro and micro reforms is of some importance. Thus, even though our model cannot formally handle macro issues, it is important to consider some of the most important elements that have been taken into account in the analysis of structural reform in countries that have not achieved macro stability.

Some new empirical evidence suggests that many failed liberalization attempts in the LDCs have not been the result of the reforms themselves, but of the accompanying macroeconomic policles. In fact, a number of recent cross country studies indicate that maintaining a stable macroeconomic environment is one of the most important determinants of the likelihood of success of a trade liberalization reform. 46 For example, In summarizing the recently completed World Bank research project on the liberalization experiences of 19 countries, Michaely et al. (1986) state the following:

[There are] ... extremely strong links between trade iiberalization and the accompanying macroeconomic policies. The latter appears to be special in determining the survivability of the trade liberalization.

At a practical level a particularly pressing question refers to the sequence in which these policies should be adopted: Should stabilization and trade reform be undertaken simultaneously or is a particular ordering more advisable? The answer to the sequencing question will depend greatly on the extent of the initial macroeconomic disequilibrium. In fact, the problems faced by policymakers will be vastly different in countries with low or medium inflation than in those that are experiencing high to veryhigh rates of inflation. This is because, in the first place, higher inflation is usually associated with higher relative price volatility and,

${ }^{46}$ See, for example, Michaely, Choksi and Papageorgiou (1986), Corbo and de Melo (1987), Edwards (1989e). 
thus, greater uncertainty. This, in turn, affects investment incentives and resource reallocation making liberalization in highly inflationary countries a somewhat risky proposition. Second, large macroeconomic disequilibriums will usially have effects on the structure of protection; as macroeconomic pressures mount most countries will hike tariffs and impose trade, exchange and capital controls in an effort to slow down the outflow of reserves. These trade restrictions that respond to inconsistent macro policies are sometimes called "balance of payments" motivated controls. In these cases, then, the ability to reduce the extent of external restrictions will be related to the progress made in controlling macroeconomic pressures. Final$1 y$, it is important to notice that the costs associated with a stabilization program will depend in a direct way on the initial magnitude of the macroeconomic disequilibrium; ending high inflations is usually a more difficult, protracted, and costly enterprise than defeating mild inflations (see Edwards 1989e).

A recent evaluation of World Bank's structural adjustment loans (SALs) suggests that two of the most important determinants of a successful trade liberalization reform are the control of the fiscal deficit and the behavior of the real exchange rate. ${ }^{47}$ This study shows that countries that failed to make progress on their trade reform goals were also those that were unable to implement a real depreciation. The examination of trade liberalization attempts under the sponsorship of the World Bank SALs also suggests that

${ }^{47}$ A large percentage of World Bank SAls include trade liberalization as a condition for fund disbursements. The paper by Edwards (1989e), which served as background for a World Bank trade policy study, dealt with 24 countries that received SALs between 1979, and 1985. The countries included in that study are: Chile, Korea, Jamaica, Mauritius, Mexico, Turkey, Bangladesh, Colombla, Cote d'Ivoire, Ghana, Kenya, Madagascar, Morocco, Panama, Philippines, Senegal, Guyana, Malawi, Pakistan, Thailand, Togo, Yugoslavia, Zambia and Zimbabwe. 
investment behaves very differently in successful and unsuccessful countries. Those countries that met their liberalization goals experienced major surges in investment, while those that failed in opening up their economies experienced significant drops in investment. ${ }^{48}$ For successful liberalizers the investment/GDP ratio was 20.98 three years prior to the reform and 29.48 three years after the reform. On the other hand, for the case of "unsuccessful countries" these figures were 28.48 and 19.78 . respectively.

When dealing with the interaction between liberalization and stabilization policies, it is important to clearly specify the extent of macroeconomic disequilibrium that the country is facing. This will largely dictate the most desirable policy package, including the sequencing of different measures. Along these lines Edwards (1989e) has recently argued that the optimal policy mix will differ in countries with mild, high and very high inflations. Generally speaking, in mildly inflationary countries trade reform policies can be implemented quite independently of the macroeconomic achievements. As the data from the recent World Bank program countries has shown, at low levels of inflation trade liberalization developments are fairly independent of macroeconomic variables (the main exception being the real exchange rate). 49

In the case of high inflation countries, however, a prudent strategy is to proceed more slowly. Initially, while the process of controling the fiscal deficit is underway and inflation has not been fully subdued, it is

${ }^{48}$ It should be noticed, however, that it is not possible to exactly know the extent to which the drop in investment is due to the macro disequilibrium.

${ }^{49}$ This point has also been made by Krueger (1981). 
recommended eliminating some of the controls and external distortions. In particular, at this stage it is usually desirable to tackle those restrictions that had been imposed solely for "balance of payments" motives. More drastic trade reform measures (i.e., those dealing with restrictions originally imposed for resource allocation motives) should generally be postponed until macroeconomic equilibrium is achieved.

The main rationale behind the above recommendation has to do with the "competition of instruments" problem. In a highly inflationary context some policy measures conducive to attaining macroeconomic stability will tend to hinder the liberalization goals. In fact, one of the most important sources of tension between stabilization and liberalization programs resides in the fact that a successful liberalization requires a real exchange rate depreciation, while disinflations have often resulted in an appreciation of the real exchange rate (Edwards, 1989e). Historically, the episodes of disinflation with real exchange rate appreciation have mainly been a result of stabilization programs that relied on some form of fixed nominal exchange rates to provide an anchor to expectations and domestic prices. ${ }^{50}$ As mentioned in Section 3.4 above, a second source of "competition of instruments" refers to the role that trade taxes play as a revenue source in the developing countries. In many cases the elimination of tariffs will result in a decline in tax revenues and, thus, in an increase in the fiscal deficit, putting positive pressure on inflation. In countries with a large public debt there is a third potential source of confilict. If liberalization is accompanied by a real devaluation -. which is the recommended policy

${ }^{50}$ In his discussion of the French stabilization under Poincare, Sargent (1986) concludes that pegging the nominal exchange rate might still be a very efficient way of stabilizing a small open economy. See Edwards (1989e) for an empirical analysis of this proposition. 
from the external sector perspective -- the real cost of servicing the debt will increase, putting more pressure on the deficit, and jeopardizing the inflationary goals.

As the prevailing level of inflation becomes higher and higher the possibility of major tradeoffs between the goals of stabilization and trade reform increases. In addition to the real exchange rate tradeoff discussed above, in the case of very rapid inflations (above 100 percent per year), three other sources of conflict between the goals of the two policles, related to relative price variability, interest rate behavior and wage rate indexation, can play a very important role. As Fischer $(1986,1987)$ has emphasized, an important consequence of rapid inflation is that relative prices become highly variable. This enhances the degree of uncertainty in the economy and has a negative impact on investment decisions. The process of sectoral allocation of capital can, indeed, be seriously disrupted with some investment going into the "wrong" sectors. In fact, a recent empirical investigation has found that those countries with a higher variability of the relative price of tradables to nontradables have tended to have a lower aggregate investment ratio than those nations with more stable relative prices (Edwards 1989e). All of this, of course, suggests that the 1iberalization objectives may be hindered if the reform is attempted before the macroeconomy has been stabilized. As a consequence of this a number of authors, most notably Stanley Fisher, have argued that under conditions of very high inflation liberalization reforms should be postponed until the macroeconomic environment has regained its stabllity.

Table 2, which is taken from Edwards (1989e), provides a summary of the policy implications regarding the sequencing of micro reforms and macro stabilization. Most OECD nations fall in the first category of mild 
TABLE 2

Macroeconomics and Trade

Liberalization Policies:

Some Policy Recommendations For The LDCs

Initial Macro

Diseguilibrium

1. Mild Inflation ( $\leq 358$ )
2. High Inflation (4081008)

3. Very High Tnflation (above 1008)

Devaluation

Yes. Stepwise devaluation may be advisable. Care should be taken that RER is devalued in an amount called for by liberalization

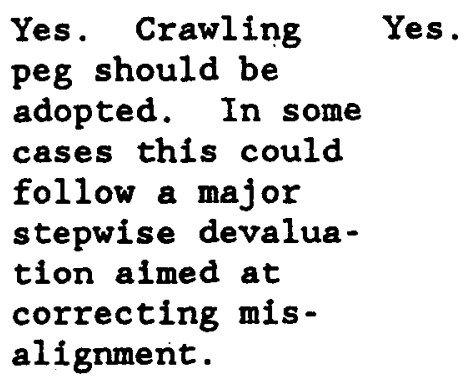

Yes. Crawling Yes.

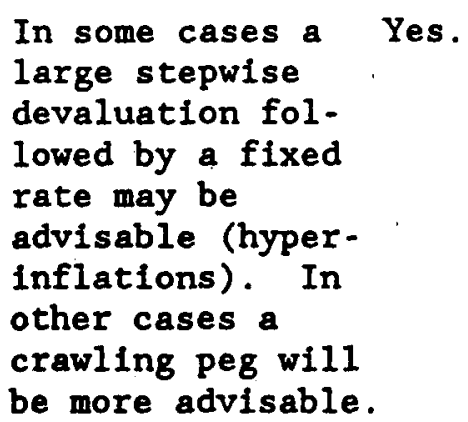

Balance of Payments Motivated Restrictions

Usually nonexisting or very low. generally improve revenues $\&$ help reduce the fiscal deficit.

Should be reduced simultaneously with stabiliz. ation.

In some cases their reduction should be postponed until some macro order is regained. In others, some restrictions can be reduced simul. taneously with stabilization.

\section{Resource Allocation Pro- tection Levels \\ Can be reduced independently of stabilization policies. Care should be taken, however, in re- placing tariffs as revenue devices.}

Should be postponed until the most pressing macro pressures subside. In some cases the tax system should be reformed.

Should be postponed until macro equilibrium is attained. Revenue considerations will be important in some countries

Source: Edwards (1989e). 
inflation countries. This means that for these nations there is only a tenuous relationship between macro and micro reforms; under most circumstances the latter can be undertaken somewhat independently of the macro situation. This does not mean, however, that the basic budget constraints,

or the real exchange rate equilibrium, for that matter, can be violated. In fact, if this does happen it is highly likely that serious credibility problems will evolve, eventually harming the sustalnabllity of macro reforms .

\subsection{Where Do we Go From Here?}

Although the model presented in this paper provides a very general framework for analyzing some of the most important welfare ramifications of structural reforms, it falls short of providing detailed and unequivocal evaluations of specific sequencings. In order to accomplish this goal we suggest that, as a first and crucial step in the process of policy evaluations, models similar to the one presented here are built so that they could be calibrated and simulated for alternative sequences. In this way it would be possible to have a clear sense of the final effects of alternative reform strategies. The simulation of these fully optimizing welfare based models could be considered as the first step in a process consisting of the construction of a family of models. As newer models are built, more subtle aspects of the discussion, such as the existence of tradeoffs between macro and micro goals and the existence of credibility problems, could be added.

We believe that undertaking simulations with models based on the one presented here - - in fact, maybe with a three period extension of the model derived in Appendix A - - has a number of advantages over the other alternatives available at this time. First, this type of model is truly intertemporal in a way that most Computational General Equilibrium (CGE) 
models are not. 51 second, recommendations stemming from this type of model are strictly and rigorously based on welfare considerations, in a way that macro simulation models such as those developed by Khan and Zahler (1983, 1985, 1987) are not. In fact, most macroeconomic models of that type are based on highly ad-hoc assumptions. Finally, the simplicity of our model is another of its virtues. It is, in fact, the minimal formal welfare framework that can be seriously used for this kind of analysis. Being simple, however, implies that it is not a black box and that we can provide serious and meaningful interpretations to every one of the channels and effects involved. As more sophisticated models are built, 1t would be advisable to first add adjustment costs. A second promising extension would be to introduce uncertainty regarding the sustainability of the policy reforms. The combination of adjustment costs and lack of credibility would allow us to deal with the type of result currently discussed in the hysteresis literature. Finally the models would greatly benefit from the addition of a monetary sector. Unfortunately, this is not an easy thing to do in an optimizing framework. Naturally these types of simulations will require the gathering of a number of key information, including intertemporal elasticities of substitution in consumption, factor intensities, intratemporal elasticities and so on. The task of obtaining these coefficients is not easy; however, it should be kept in mind that similar requirements are also present in alternative approaches. Finally, it is worth emphasizing again and again that the result obtained from simulations using this, or for that matter any other, model should be taken with one (or more) grains of salt. After all, reality is always much more complicated.

${ }^{51}$ See Dervis, de Melo and Robinson (1981). 


\section{APPENDIX A}

\section{A Real Intertemporal General Equilibrium Model of Structural Reform}

\section{A.I Introduction}

The purpose of this Appendix is to present a formal real intertemporal optimizing model to analyze the welfare consequences of policies aimed at liberalizing and deregulating some key sectors in a distorted economy. Although the main objective of the model is to focus on the final welfare effects, this framework can be easily used to analyze the behavior of some other crucial variables, including interest rates, the trade account, employment and the real exchange rate. However, since the model is real, it cannot deal with macroeconomic issues such as inflation or changes in other nominal variables.

This model provides the formal underpinnings for the discussion provided in the text, and concentrates on a fictional country, whose economic structure is somewhat similar to what we have called a G-type economy. More specifically, we assume that this economy is characterized by macroeconomic stability, low distortions on commodity trade, a distorted labor market, a regulated services sector, and capital controls. ${ }^{52}$ An effort is made to capture some of the more important subtleties of the real (microeconomic) sectors. Special care is placed on highlighting the interaction between distortions affecting intratemporal decisions and those that affect intertemporal decisions. In order to concentrate on fundamentals, in the body of the analysis we make a series of simplifying assumptions. Later, however, we discuss how the model can be amended to

52 of course, the G-economy defined in the text did not have capital controls. Our formal model, then, is more general. 
incorporate a more sophisticated structure.

As in the analytical framework developed in Section 3 of the text we assume that this economy is subject to four basic distortions. (1) Real wage rigidities that generate unemployment. In the body of the discussion we assume that this labor market distortion takes the form of a minimum wage expressed in terms of the exportable good. Later, however, we briefly discuss the case of nominal wage indexation to a general price index. (2) Regulations on the services sector. This distortion is assumed to take the form of a tax.. Services, on the other hand, are treated as a nontradable good whose market has to clear in every period. (3) Financial sector regulations that take the form of controls on capital movements and that result in an interest rate differential between domestic and world interest rates and, (4) Low import tariffs that distort resource allocation in the import competing sector.

\section{A.II The Mode1}

In this section we formally present the benchmark model. The country under consideration is a small open economy that faces given world prices of tradable goods and given world interest rates. There are three goods .exportables (X), importables (M) and nontradables (N), and two periods -. the present (period 2) and the future (period 2). There are capital controls which are reflected in a differential between the domestic real interest rate $(r)$ and foreign real interest rate $\left(r^{*}\right)$. There are a large number of producers and (identical) consumers, and perfect competition prevails. The labor market is distorted by a minimum wage $\bar{w}$, which we assume is in effect in both periods. In the tradition of international trade theory, it is assumed that the supply of labor, as well as that of the other 
factors, is inelastic. Besides labor, it is assumed that there is capital and natural resources. Initially, and in order to simplify the discussion, we assume that there is no investment. Later, however, we provide a detalled discussion on how the formal introduction of investment will affect the results obtained. 53

Consumers maximize utility subject to their intertemporal budget constraint, whereas firms maximize profits subject to existing constant returns to scale technology, availability of factors of production, and the predetermined minimum wage. Assuming that the utility function is time separable, with each subutility function homothetic and identical, the representative consumer problem can be stated as follows: ${ }^{54}$

$$
\max v\left(u\left(c_{N}, c_{X}, c_{M}\right) ; U\left(c_{N}, c_{X}, c_{M}\right)\right)
$$

subject to:

$$
c_{X}+p c_{M}+f c_{N}+\delta\left(C_{X}+P c_{M}+F c_{N}\right) \leq \text { Wealth, }
$$

where the lower case letters refer to first. perfod variables and the upper case letters refer to second period variables. The price of exportables has been taken to be the numeraire, (e.g., $\left.p_{X}-P_{X}-1\right) . V$ is the intertemporal welfare function; $u$ and $U$ are periods 1 and 2 subutility functions assumed, as pointed out, to be homothetic and identical. $c_{X}, c_{M}, c_{N},\left(c_{X}, c_{M}\right.$ and $C_{N}$ ) are consumption of $X, M$ and $N$ in period one (two). $f$ and $F$ and $p$ and $P$ are the prices of nontradables and importables relative to exportables faced by consumers in periods 1 and 2 , and are inclusive of the

${ }^{53}$ In this type of fully optimizing model with constant returns to scale technology, there is a problem with having both minimum wages in both periods and investment. See for example, Svensson (1984) and the discussion below.

${ }^{54}$ An upward sloping supply of labor can be added into the analysis simply by adding leisure to our utility function. See Edwards (1989d). 
tax on $N$ and the tariff on $M$. $\delta$ is the domestic discount factor equal to $(1+r)^{-1}$. Since there is a tax on foreign borrowing, the domestic real interest rate $r$ is higher than the world interest rate. The differences between these two rates is given by the tax $(\sigma)$ on capital movements: $r=r * 0$.

Wealth is the discounted sum of consumer's income in both periods. Income, in turn, is given by: (1) income from labor services; (2) income from the renting of capital stock, and of natural resources that consumers own to domestic firms; and (3) income obtained from government transfers. These, in turn, correspond to the government's revenue from tariffs, taxes on nontradables and capital flows in each period. The solution to the consumers optimizing problem is conveniently summarized by the following intertemporal expenditure function:

$$
E=E(\pi(I, P, f), \delta * \Pi(1, P, F), V) \text {. }
$$

where $\pi$ and $\Pi$ are exact price indexes for periods 1 and 2 . Under the assumptions of homotheticity and separability these price indexes correspond to unit expenditure functions (Svensson and Razin, 1983; Edwards and van Wijnbergen, 1986). Given our assumption of a time separable utility function, total expenditure in periods 1 and 2 are always substitutes.

On the other hand the producers maximization problem can be summarized with the ald of restricted revenue functions, which give us the maximum revenue that firms can obtain after making all the optimal decisions in terms of hiring and production given the distortion in the labor market (see Neary 1985). 55 Denoting $r$ and $R$ as periods 1 and 2 restricted revenue

${ }^{55}$ An important property of restricted revenue functions is that they directly incorporate the effect of unemployment on earnings. into the intertemporal budget constraint. Consequently there is no need to deal with 
functions; $q$ and $Q$ as the prices of nontradables faced by producers; $s^{i}$ and $s^{i}$ as the quantities supplied, and $k$ and $k$ as other (nonlabor) factors of production, we have that:

$$
r=r(1, p, q, l(1, p, q, \bar{w}))
$$

and

$$
R-R(1, P, Q, L(1, P, Q, \bar{w}))
$$

where $\ell()$ and $L()$ are employment functions in periods 1 and 2 . . Some useful and well known properties of revenue functions are that their derivatives with respect to goods prices are equal to supply functions, and that their derivatives relative to factors are equal to the marginal product of that factor.

The fact that there is a tax on the nontradables market is captured by the inclusion of different prices of nontradables in the expenditure and revenue functions ( $f$ and $q$, respectively). The difference between producers and consumers prices is, of course, given by the tax on nontradables $\tau^{i}$ :

$$
\begin{aligned}
& f=q+r^{1} \\
& F=Q+r^{2}
\end{aligned}
$$

The complete model is then given by the following set of equations (where subindexes refer to partial derivatives with respect to that variable):

$$
\begin{aligned}
& r(1, p, q, \ell(1, p, q, \bar{w}))+\delta R(1, P, Q, L(1, P, Q, \bar{w})) \\
+ & \operatorname{TRANS}-E(\pi(1, p, f), \delta \Pi(1, P, F), V)
\end{aligned}
$$

issues related to rationing. 


$$
\begin{aligned}
& \text { TRANS }=\tau^{1} r_{q}+\delta r^{2} R_{Q}+b C A+t^{1} M^{1}+\delta t^{2} M^{2} \\
& b=\delta *-\delta \\
& C A=R-\Pi E_{\delta \Pi} \\
& f=q+r^{1} ; \quad F=Q+r^{2} \\
& r_{q}=E_{f} \\
& R_{Q}=E_{F} \\
& p=p *+t^{1} ; \quad P=P *+t^{2} \\
& M^{1}=\left(E_{P}-r_{P}\right) ; \quad M^{2}-\left(E_{P}-R_{P}\right)
\end{aligned}
$$

Equation (A.6) is the intertemporal budget constraint, and says that the present value of income (the left hand side) has to equal the present value of expenditure (the right hand side). TRANS is the present value of government transfers to the public and is given by equation (A.7). Here $r^{1} r_{q}$ is period 1 tax revenue from the nontradables market $\left(\tau^{1}\right.$ is the tax rate in period 1 and $r_{q}$ is the equilibrium quantity produced and consumed in that period); $\delta \tau^{2} R_{Q}$ is the present value of period 2 nontradables tax revenues, $b C A$ is the present value of the tax on foreign borrowing, where $b$ is the present value of the tax per unit borrowed and is equal to $(\delta *-\delta)$, and CA is the current account in period 2, which is defined in equation (A.9) as period 2 income minus expenditure. This means that, since in this model there is no investment, the current account is equal to savings in each period. Finally, $t^{1} M^{1}$ and $\delta t^{2} M^{2}$ in equation (A.7) are revenues from import tariffs; $t^{1}$ is the tariff rate in period 1 , and $M^{i}$ are imports in 1 and are defined in equation (A.14) as the excess demand for importables in each period. 
Equation (A.10) provides the linkage between consumer and producer prices for nontradables. Equations (A.11) and (A.12) state that the nontradables goods market has to clear in each period -. $r_{q}$ and $R_{Q}$ are quantities produced of these goods, while $E_{f}$ and $E_{F}$ are the quantities demanded.

An important characteristic of this model is that there is intial unemployment. In fact, the conditions prevailing in the labor market are captured by Figure 2 in the text. Notice that, as presented above, the model assumes that the minimum wage $\bar{w}$ is in effect in both periods. of course, this need not be the case, and we can easily handle the case where there is a minimum wage in period 1 only. In fact, this is indeed what we do below when we explicitly introduce investment into the analysis.

\section{A.III The Welfare Effects of Liberalization and Deregulation}

The model developed in Section A.II can be used to analyze a number of important welfare questions related with the sequencing of structural reforms. For example, in principle this model could be used to rank, in terms of welfare, different combinations of taxes and distortions. 56 Moreover, this model can be used to evaluate the welfare consequences of any combination of policies characterized by: (a) financial sector deregulation -. a reduction in the financial sector tax $\sigma$ (or b); (b) services sector deregulation, characterized by a reductions in the tax on nontradables r; (c) labor market deregulation, captured by a reduction of the minimum wage $\bar{w}$; and (d) import tariffs reform (a reduction in $t^{i}$ ).

${ }^{56}$ This, however, would require assuming a specific form of the welfare function and assuming values for the key parameters. These issues are addressed in some detail below. 
Totally differentiating equation (A.6), and simplifying terms, we obtain the following key equation that captures the different channels through which structural reforms will affect welfare in this economy (where as before subindexes refer to partial derivatives):

$$
\begin{aligned}
E_{V} d V & =t^{1} d^{1}+\delta t^{2} d^{2} \\
& +\tau^{1} r_{q q} d q+\delta \tau^{2} R_{Q Q} d Q \\
& +b d C A+w^{1} d \ell+\delta \dot{w}^{-2} d L \\
& +\tau^{1} r_{q p} d t^{1}+\delta \tau^{2} R_{Q P} d t^{2} \\
& -\tau^{2} R_{Q} d b-t^{2} M^{2} d b \\
& +\tau^{1} r_{q \ell} d \ell+\delta \tau^{2} R_{Q L} d L
\end{aligned}
$$

Although this is not a reduced form .. since many of the RHS variables are endogenous - - it is a highly informative equation. The first two terms of the right hand side capture the welfare effects stemming from changes in imports in periods 1 and 2 . If as a result of whatever reform we are analyzing either $M^{1}$ or $M^{2}$ increase we will have welfare gains. These, in turn, will be proportional to the initial distortions. The next two terms $\left(r^{1} r_{\mathrm{qq}} \mathrm{dq}\right.$ and $\left.\delta r^{2} \mathrm{R}_{\mathrm{QQ}} \mathrm{dQ}\right)$ summarize the welfare consequences of changes in the equilibrium quantities transacted in the nontradables sectors. Naturally, these changes operate via changes in the prices of $N$, $q$ and $Q$. If, for example, a reform raises these prices (e.g., $d q>0$ and $d Q>0$ ) we will have positive social welfare effects (since $r_{q q}$ and $R_{Q Q}$ are positive) which will be proportional to the initial distortions in this market. The next term bdCA captures the welfare consequences of changes in period 2 current account; if the reform reduces the size of the current account, total welfare will decline. This is because reductions in 
the CA will amplify the preexisting distortion stemming from the tax on capital mobility. The next two terms $\left(\dot{w}^{1} \mathrm{~d} l\right.$ and $\left.\delta \dot{w}^{2} \mathrm{dL}\right)$ deal with the labor market and state that if a reform increases employment in either period, social welfare will increase. Naturally, since $M^{1}, M^{2}, q, Q, C A, \ell$ and $L$ are endogenous variables, in order to obtain the exact expressions for these welfare changes we will need to solve the complete model. 57

The final six terms of equation (A.15) - $\left[\tau^{1} r_{p q} d t^{1}+\delta r^{2} R_{Q P} d t^{2}-\right.$ $\left.\tau^{2} \mathrm{R}_{\mathrm{Q}} \mathrm{db}-\mathrm{t}^{2} \mathrm{M}^{2} \mathrm{db}+\tau^{1} \mathrm{r}_{\mathrm{q} \ell} \mathrm{d} \ell+\delta \tau^{2} \mathrm{R}_{\mathrm{QL}} \mathrm{dL}\right]$ - are indirect terms originated from the interaction among the different distortions. Their magnitude, then, will basically depend on the sign of several cross elasticities.

In order to provide further insights of the working of this framework, we will look in detail at the effects of two specific reforms discussed in the text: (1) an anticipated future tariff reduction in a G-type economy analyzed in Section 4.1.1); and (2) the optimal degree of financial intervention in an economy with labor market distortions in period 1 only (which was the subject of Section 4.2).

\section{A.III.1 Anticipated Tariff Reductions}

Assume the case of a G-type economy where capital movements are not restricted. This means that $\delta-\delta *$ and that $b=0$. Consider now the anticipated tariff reform exercise discussed in the text. This means that:

$$
d \tau^{1}-d \tau^{2}=d t^{1}-0
$$

and,

$$
d t^{2}<0
$$

${ }^{57}$ For the solution of similar .. although admittedly simpler -. models see Edwards $(1989 a, b, c)$. 
The effects of this (anticipated) structural reform on social welfare will be given by:

$$
\begin{aligned}
& E_{V} \frac{d V}{d t^{2}}-\delta * t^{2} \frac{d M^{2}}{d t^{2}}+t^{1} \frac{d M^{1}}{d t^{2}}+\delta * r^{2} R_{Q P} \\
& +\tau^{1} r_{q q} \frac{d q}{d t^{2}}+\delta * \tau^{2} R_{Q Q} \frac{d Q}{d t^{2}} \\
& +-1 \frac{d l}{d t^{2}}+\delta * w^{-2} \frac{d L}{d t^{2}} \\
& +\tau^{1} r_{g l} \frac{d l}{d t^{2}}+\delta * \tau^{2} R_{Q L} \frac{d L}{d t^{2}}
\end{aligned}
$$

where, at a very general level, the interpretation of the RHS terms is the same as that given to them in equation (A.15). However, we can now classify these nine RHS terms into the three categories of welfare effects proposed in the text: (i) direct welfare effects; (ii) indirect intratemporal effects; (iii) indirect intertemporal effects. 58

(i) Direct Welfare Effects

The term $\delta * \varepsilon^{2} \mathrm{dM}^{2} / \mathrm{dt}^{2}$ is the direct welfare effect, and it represents the change in the equilibrium amount transacted in the reformed market. This, of course is a general equilibrium change and, as such, captures all forces affecting imports in that period, including those that work their way through other markets. In order to gain further insights into the forces affecting imports in period 2 we can write $\mathrm{dM}^{2} / \mathrm{dt}^{2}$ as follows:

$$
\frac{d M^{2}}{d t^{2}}-E_{P P}+E_{P f} \frac{d f}{d t^{2}}+E_{P F} \frac{d F}{d t^{2}}
$$

${ }^{58}$ Notice that strictly speaking this classification is only approximate, since in some cases we get a mixture of intertemporal and intratemporal elasticities. 


$$
\begin{aligned}
& -R_{P P}-R_{P Q} \frac{d Q}{d t^{2}} \\
& -R_{P L} \frac{d L}{d t}+E_{P V} d V
\end{aligned}
$$

where $E_{P f}$ is an intertemporal demand term, and where $\mathrm{df} / \mathrm{dt}{ }^{2}, \mathrm{dF} / \mathrm{dt}^{2}$ and $\mathrm{dQ} / \mathrm{dt}^{2}$ are the real exchange rate effects of the tariffs change, which as established by Edwards $(1989 a, c)$ are, under most circumstances, positive. Notice that in this expression for the change in imports we have, once again, the induced change in employment $\mathrm{dL}^{2} / \mathrm{dt}^{2}$. Below we provide an exact expression for it.

\section{(ii) Intratemporal Indirect Effects}

In equation (A.16) the terms $\delta * \tau^{2} \mathrm{R}_{\mathrm{QP}}, \delta *_{\tau}{ }^{2} \mathrm{R}_{\mathrm{QQ}}\left(\mathrm{dQ} / \mathrm{dt}{ }^{2}\right), \delta * \mathrm{w}^{2} \mathrm{dL} / \mathrm{dt}{ }^{2}$ and $\delta *_{\tau}{ }^{2} \mathrm{R}_{\mathrm{QL}}\left(\mathrm{dL} / \mathrm{dt}{ }^{2}\right)$ are indirect effects that manifest themselves in the same period as the reform .. that is in period 2. This, of course, is the reason why each of them appears multiplied by the discount factor.

Let us now concentrate our attention on the employment term $\delta * w^{2}$ $d L / d t^{2}$. It says that if the reform increases (decreases) employment in period 2, there will be a positive (negative) contribution to total social welfare. In order to gain some insights into the way in which this employment effect works, it is convenient to write dL as follows:

$$
\frac{d L}{d t^{2}}-L_{P}+L_{Q}\left(\frac{d Q}{d t^{2}}\right)
$$

where ${ }^{59}$

$$
L_{P}=\frac{-R_{P L}}{R_{L L}}
$$

${ }^{59}$ See Neary (1985), and Edwards and Ostry (1989). 


$$
L_{Q}=\frac{-R_{Q L}}{R_{L L}}
$$

$R_{L L}$ is the slope of the marginal product of labor schedule and is negative. $\mathrm{R}_{\mathrm{PL}}$ and $\mathrm{R}_{\mathrm{QL}}$, on the other hand, are Rybczynski terms that capture what will happen to output of $M$ and $N$ ( $R_{P}$ and $R_{Q}$ respectively) if there is an increase in the labor force. Their sign is undetermined s priori and depend on relative factor intensities. The problem, however, is that in our three-by-three model determining the signs of the Rybczynski terms is not trivial. However, as Leamer (1987) has shown, if nontradables is the most labor intensive sector - - both with respect to capital and with respect to natural resources - $R_{Q L}$ will be positive. This means that $R_{P L}$ can be either positive or negative. A necessary (although not sufficient) condition for it to be positive is that importables is the second most labor intensive sector. If we assume that $R_{P L}$ is also positive, then tt follows that we obtain the textbook result in which reform reduces employment in both periods and, as such, constitutes a welfare reducing move.

\section{(iii) Indirect Intertemporal Effects}

The other four terms in equation (A.16) $\cdots t^{1} \mathrm{dM}^{1} / \mathrm{dt}^{2}, \tau^{1} \mathrm{r}_{\mathrm{qq}}\left(\mathrm{dq} / \mathrm{dt}^{2}\right)$, $\bar{w}^{-1}\left(\mathrm{~d} \ell / \mathrm{dt}^{2}\right)$ and $\tau^{1} \mathrm{r}_{\mathrm{q} \ell}\left(\mathrm{d} \ell / \mathrm{dt}{ }^{2}\right)$.. correspond to the indirect intertemporal effects discussed extensively in subsection 4.1 .1 of the text.

\section{A.III.2 Relaxing Capital Controls}

Consider now the exercise discussed in Section 4.2 of the text: a change in the extent of capital controls in an economy with labor market distortions in period 1 only. In that discussion we determined that, under our assumptions regarding relative factor intensities, the optimal policy consisted of a (small) subsidy on borrowing. The reason was that this 
subsidy would tilt consumption towards the present, generating an increase in that period's level of employment.

Formally, the welfare effect of this small subsidy on borrowing, or small increase in $\delta$, is given by:

$$
E_{v} d v=r_{\ell} \ell_{q}\left(\frac{d q}{d \delta}\right)
$$

where $r_{\ell}$ is the derivative of period 1 revenue function with respect to $\ell$, and is positive. ${ }^{60} \ell_{q}$ is, as before, the derivative of the revenue function with respect to the relative price of nontradables and under our assumptions on labor intensities is positive and, finally, (dq/d $\delta$ ) is the real exchange rate effect of relaxing capital controls and is also positive. $^{61}$ A crucial feature of equation (A.20) is that it implies that all the action comes through the effect of the change in $\delta$ on the real exchange rate, or relative price of nontradables $q$. This means that in models with no nontradables, changes in the extent of capital controls will have no effect on employment and, thus, there will be no interaction between the labor market and foreign borrowing distortions.

Notice that the preceding discussion has established that it is optimal (in a second best sense) to impose a subsidy on foreign borrowing when there are no initial taxes on borrowing and when the minimum wage applies only to period 1. However, a more general setting, where the minimum wage applies to both periods, and the initial value of $b$ is greater than zero, this need not be the case. The optimal level of the tax (subsidy) on forelgn borrowing in this general case is obtained from a generalized version of

${ }^{60}$ Since $r_{f}$ is evaluated at the actual level of employment, it is equal to the minimum wage $\bar{w}$.

${ }^{61}$ See Edwards (1989b). 
equation (A.20). After simple manipulations we find that the change in welfare resulting from a higher $\delta$ is given by:

$$
\begin{aligned}
\frac{d V}{d \delta}\left(E_{\mathrm{v}}+b E_{V I}\right)= & -b \Pi^{2} E_{I I I}-b \Pi E_{\pi \Pi^{\pi}}{ }_{q}\left(\frac{d q}{d \delta}\right) \\
& -b \delta \Pi E_{I I I} \Pi_{Q}\left(\frac{d Q}{d \delta}\right)+r_{\ell}{ }^{\ell}\left(\frac{d q}{d \delta}\right)+\delta * R_{L} L_{Q}\left(\frac{d Q}{d \delta}\right)
\end{aligned}
$$

where as before the $\ell_{\mathrm{q}}$ and $\mathrm{L}_{\mathrm{Q}}$ are equal to:

$$
\ell_{q}=-r_{\ell q} / r_{\ell \ell} ; \quad L_{Q}=-R_{L Q} / R_{L L} \text { and positive. }
$$

The intuition behind equation (A.21) is simple. The first three terms have $a$ "b" attached to them and capture the effects of a higher $\delta$ on the intertemporal allocation of expenditure. For instance, the first term $-b \Pi^{2} E_{\mathrm{III}}$ is positive; the reason is that due to the existence of a positive initial b, expenditure in period 1 is "too low". A higher $\delta$ will result in an increase in period 1 expenditure, moving it towards the optimal level. The second and third terms capture indirect expenditure terms and operate via the effects of changes in $\delta$ on the equilibrium real exchange rates. Their interpretation is similar to that of the first term. The last two terms in (A.21) are the employment effects. They state that to the extent that lowering the tax (raising $\delta$ ) generates an increase in the real exchange rate there will be a positive employment effect.

From equation (A.21) the optimal tax (subsidy) on foreign borrowing can be found: 62

$$
b *-\frac{r_{\ell} \ell_{q}\left(\frac{d q}{d b}\right)+\delta * R_{L} L_{Q}\left(\frac{d Q}{d b}\right)}{-\Pi^{2} E_{m I}+\Pi E_{\pi \Pi^{\pi}}\left(\frac{d q}{d b}\right)+\delta \Pi E_{I I I} \Pi_{Q}\left(\frac{d Q}{d b}\right)}
$$

${ }^{62}$ For further discussions on optimal intervention in the capital market see Edwards and Ostry (1989). 
which can be positive or negative. Notice that as before the real exchange rate plays a crucial role. Edwards $(1989 a, b)$ has shown that an increase in b will always result in a depreciation of the real exchange rate in period 1 (i.e., dq/db<0), while period $2^{\prime}$ 's real exchange rate can go either up or down $(d Q / d b \lessgtr 0) .^{63}$ From this equation it is easy to establish the conditions required for the optimal $b$ to be positive.

\section{A.IV Evaluating Alternative Sequencings of Reform}

In principle, the intertemporal model developed in this Appendix, or some straightforward variants of it, can be used to evaluate the welfare effects of alternative sequencing scenarios. As pointed out in the text at a simple, or almost trivial level, the optimal sequencing will be the one that results in a higher level of social welfare. That is, if we consider three possible sequencings $A, B$ and $C$, sequencing $A$ will be preferred to $B$ and $C$ if

$$
\mathrm{V}(\mathrm{A})>\mathrm{V}(\mathrm{B})
$$

and $V(A)>V(C)$.

of course, from a practical point of view there are two problems with this ranking. First, we know that within the context of our model the first best sequencing is characterized by a simultaneous and immediate liberalization of all markets. For this reason, in order to add structure to this problem it is necessary to assume that for some (not fully specified) reason the existing distortions cannot be undone until some point in the future. Once this is assumed we move to a second best context, and the sequencing

${ }^{63}$ It is important to point out that the fact that $b *>0$ does not mean that a tax on foreign borrowing will be the optimal way to deal with labor market distortions. 
question becomes an interesting one. The second limitation with using criterion (A.23) and thus finding the actual levels of welfare, is that it is necessary to assume specific forms for the welfare function. Although this can be done -- and, in fact, this is the recommendation we made in Section 5 of the text -. this type of exercise is well beyond the scope of the present paper. Once we decide not to follow this route we are restricted to looking at changes in welfare instead of at its absolute level. This, of course, is not a trivial task in a two-period model. In the present section, we develop a methodology that helps shed some formal light on the sequencing of structural reforms for what we have called a G-economy. Although no definitive theorems are derived, the discussion is useful. We start by making two key assumptions. First, we assume that in: the long-run (period 2) all markets are liberalized. Second, we assume that the labor market restrictions are the last ones to be lifted. Within this framework we analyze two alternative sequencings: in sequencing $A$ the tradables (importables) sector is liberalized first, this is followed by a lifting of restrictions in the services (nontradables) sector and ends with the liberalization of labor markets. Sequencing $B$, on the other hand, starts with a reform in the service sector followed by a liberalization in the importables sector and also ends with the elimination of restrictions in the labor markets. Table A.1 summarizes these two sequences.

As said before, if some simplifying assumptions are made with respect to the specific form of the welfare function $v$, and the model in Section A.II is calibrated, we would be able to find the actual levels of welfare under both sequencings. However, given the level of generality of this study, we do not have enough information to perform this exercise and, thus, have to limit ourselves to the analysis of changes in the level of welfare. 
TABLE A. 1

Alternative Sequencing Scenarios in a G-Type Economy ${ }^{*}$

Market

Labor

Importables

Nontradables
Sequence A

(Trade Restrictions First)

$$
\text { Initial }
$$

Situation

$$
\text { Period }
$$

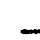

$\bar{w}>w^{e q}$

$\bar{w}>w^{e q}$

Period

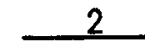

$t>0$

$t=0$

$r>0$

$\tau>0$

$w-w^{e q}$

$t=0$

$r=0$
Sequence B

\begin{tabular}{|c|c|c|}
\hline $\begin{array}{c}\text { Initial } \\
\text { Situation }\end{array}$ & $\begin{array}{c}\text { Period } \\
1 \\
\end{array}$ & $\begin{array}{c}\text { Period } \\
2 \\
\end{array}$ \\
\hline$>w^{e q}$ & $\dot{w}>w^{e q}$ & $w=w^{e q}$ \\
\hline$t>0$ & $t>0$ & $t=0$ \\
\hline$>0$ & $\tau=0$ & $\tau=0$ \\
\hline
\end{tabular}

(Nontradable Distortions First)

* of course, as with all discrete time models it is useful to make a distinction between beginning and end of period. For example, in sequence A we should think of the importables market as being liberalized at the end of period 1 and the nontradables sector at the beginning of period 2 . 
We will use, then, the following methodology: for one sequencing at the time we ask ourselves what is the likelihood of that particular order of reform being "optimal", given that the labor market cannot be liberalized until the very end. Technically speaking, this question amounts to the following. We take the particular sequence we are analyzing and determine what are the welfare consequences of a small relaxation of the (non-labor) distortion prevalling at the end of period 1. If, for instance we are dealing with sequencing $A$, this means that we analyze what are the welfare effects of relaxing the tax on nontradables that remained at the end of period 1. If we find that welfare decreases it indicates that sequencing $A$ is "adequate". On the contrary, if we find that social welfare increases when we relax the (nonlabor) period 1 distortion, it means that such sequencing is not adequate, and that it pays to carry out the reform of that market at the beginning of period 1. Moreover, with this methodology we are able to compute the optimal period 1 distortion for each of the two alternative sequencings.

\section{A.IV.1 "Tariffs-First" Sequencing}

Let us start with the analysis of sequencing A. As said before, in this case we assume that we have a G-type economy that has eliminated its restrictions to trade in perfod 0 , and we ask what will happen to social welfare if taxes on the services (nontradables) sector are slightly reduced. In this case the exact change in welfare is given by the following expression:

$$
\left.E_{V} \frac{d V}{d \tau^{1}}\right|^{\text {Seq.A }}=\tau^{1} r_{q q}\left(\frac{d q}{d \tau^{1}}\right)+\bar{w}^{-1}\left(\frac{d \ell}{d r^{1}}\right)+\tau^{1} r_{q \ell}\left(\frac{d \ell}{d \tau^{1}}\right)
$$


That is, the change in welfare will basically depend on the way in which the equilibrium relative price of nontradables, or real exchange rate, and the first period's employment ( $l$ ) will react to the change in taxes in period $1, \tau^{1} .\left(\mathrm{dq} / \mathrm{d} \tau^{1}\right)$ is elearly negative, while under our assumptions regarding relative factor intensities $d \ell / d \tau^{1}$ will also have a negative sign, implying that an increase in the tax on $N$ will reduce employment. This means that, conditional on tariffs having been eliminated in period 0 , it pays to implement a small reduction in period 1 taxes on nontradables. In fact, to gain further insights we can compute the "optimal second-best" period 1 tax on nontradables:

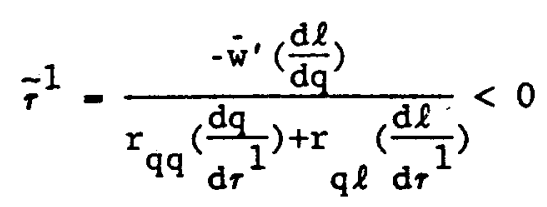

Since this optimal tax is negative this expression tells us that if tariffs have been reduced in period 0 , a welfare maximizing government should subsidize nontradables in period 1! If, however, for fiscal constraints or other reasons subsidies have to be ruled out we would be able to state a theorem that says that, under our specific assumptions:

If tariffs are eliminated first and labor market distortions are eliminated last, then it pays to eliminate nontradables taxes at the same time as tariffs. Thus, the adequate sequencing is to reform the nontradables and importable markets simultaneously.

\section{A.IV.2 "Services-First" Sequencing}

Let us now concentrate on sequencing $B$, and ask what will be the welfare consequences of relaxing the distortion on importables in an economy that has already liberalized the services sector. The welfare effect in this case is given by: 


$$
E_{V} d V-t^{l} \frac{d M^{1}}{d t^{1}}+r_{\ell} \frac{d \ell}{d t^{1}}
$$

where as before,

$$
\begin{aligned}
\frac{d M^{1}}{d t^{1}} & =\left(E_{p p}-R_{p p}+E_{p f}\left(\frac{d f}{d t^{1}}\right)+E_{p F}\left(\frac{d F}{d t^{1}}\right)\right. \\
& \left.-r_{p q} \frac{d q}{d t^{1}}-r_{p l} \frac{d l}{d t^{1}}-E_{p V} d V\right)
\end{aligned}
$$

is assumed to be positive, and where

$$
\frac{d \ell}{d t^{1}}=-\frac{r_{p l}}{r_{\ell l}}-\frac{r_{q l}}{r_{L L}}\left(\frac{d q}{d t^{1}}\right)
$$

Consequently:

Given our factor intensities assumptions, if nontradables are liberalized first, it is not clear that it will pay to reduce period 1 tariffs simultaneously. The adequate sequencing in this case is undetermined.

\section{A.v Extensions}

Although the model developed in this Appendix is quite powerful it can still be extended in various directions, making is more "realistic". Here we briefly sketch two such extensions.

\section{A.v.1 Multiple Sectors}

As pointed out in Section 3 of the text, the model can easily be extended to the case of many industries within each sector. We can think, for example, of two different types of importables with different tariff rates or, alternatively, one subject to tariffs, while the other is only subject to a consumption tax. This was, in fact, what we did in Section 3.3.1 when we discussed the issue of "competition of instruments". In the 
multiple sectors case the algebra will get more cumbersome, but the same principles applied here will be at work.

\section{A.V.2 Investment}

Since the discussion presented above has ignored investment, the current account in each period has always been equal to savings in that particular period. Investment, however, can be introduced in a straightforward fashion. Once investment is added to the analysis, the intertemporal budget constraint has to be altered and an equation describing the process governing investment decisions has to be added to our system. However, as Svensson (1984) has pointed out there is a difficulty with incorporating investment in an economy with constant returns to scale technology and minimum wages in period 2. The reason is that in that period employment and investment are jointly determined. "If there are constant returns to scale ... an arbitrarily given real future wage in equilibrium is incompatible with the given discount factor" (Svensson 1984, p. 664). The easiest way to get around this problem is to assume that the minimum wage is only in effect in period 1.

In this case denoting investment by $I$ and assuming that there is "time to build," the intertemporal budget constraint becomes:

$$
\begin{aligned}
r(1, p, q ; k, l) & +\delta * R(1, P, Q ; k+I)+\text { TRANS } \\
& -I(\delta *)-E(\pi(1, p, q), \delta * \Pi(1, P, Q), V
\end{aligned}
$$

Possibly the simplest way to deal with investment is by assuming that investment decisions are governed by the condition that in equilibrium Tobin's " $q$ " equals 1. Further assuming that investment goods correspond to the numeraire good, the investment equation can be written in the following way: 


$$
\delta * R_{k}=1
$$

The manipulation of (A.28) and (A.29) and the two conditions for equilibrium in the nontraded goods market in period 1 and 2 will now yield the corresponding expressions for welfare changes of alternative reform packages.

\section{A.V.3 Intermediate Inputs}

Until now our analysis has assumed that all three sectors produce final goods. In reality, however, numerous sectors produce intermediate inputs. Moreover, a high proportion of international trade is in intermediate goods. The existence of a distorted intermediate goods sector can be easily introduced into our formal model by using the concept of net outputs developed, among others, by Dixit and Norman (1980, pp. 160-163). If the (often used) assumption of fixed coefficients is made, our previous analysis, based on the properties of the revenue function will follow directly. Naturally in that case we would need to focus on net outputs. 


\section{APPENDIX B \\ Sector Specific Labor Market Distortions: A Diagrannatical Exposition}

The analysis presented above has assumed that the labor distortion affects all markets. This, however, need not be the case. In fact a number of authors have argued that in some of the OECD countries such as Germany, the rigid wage affects some sectors only. For instance, Burda and Sachs (1987) developed a model of the German labor market where a minimum wage affects only one sector. A limitation of the Burda-Sachs paper, however, is that they do not consider a mechanism through which the intrasectoral wage differential becomes an equilibrium differential. In this Appendix we consider the case of a minimum wage binding only in the importables sector and we concentrate on the intratemporal effects of this distortion. However, the incorporation of intertemporal considerations can be done following our previous discussion.

In order to analyze this case, the labor market diagram used previously must be somewhat modified. Figure B.1 is similar to Figure 2, except that total labor used in the importables sector is measured from the right-hand side origin $O_{M}$. The wage rate $\vec{W}_{M}$ is the minimum wage in the importable sector (that is, manufacturing) and $\dot{L}_{M}$ is employment in that sector. Curve $q q$ is a rectangular hyperbola known as the Harris-Todaro locus, along which the following equation is satisfied:

$$
\mathrm{W}_{\mathrm{N}}-\mathrm{W}_{\mathrm{X}}-\frac{\mathrm{L} M}{\mathrm{~L}_{\mathrm{M}}+\mathrm{U}} \mathrm{W}_{\mathrm{M}} \text {, }
$$


FIGURE B.1

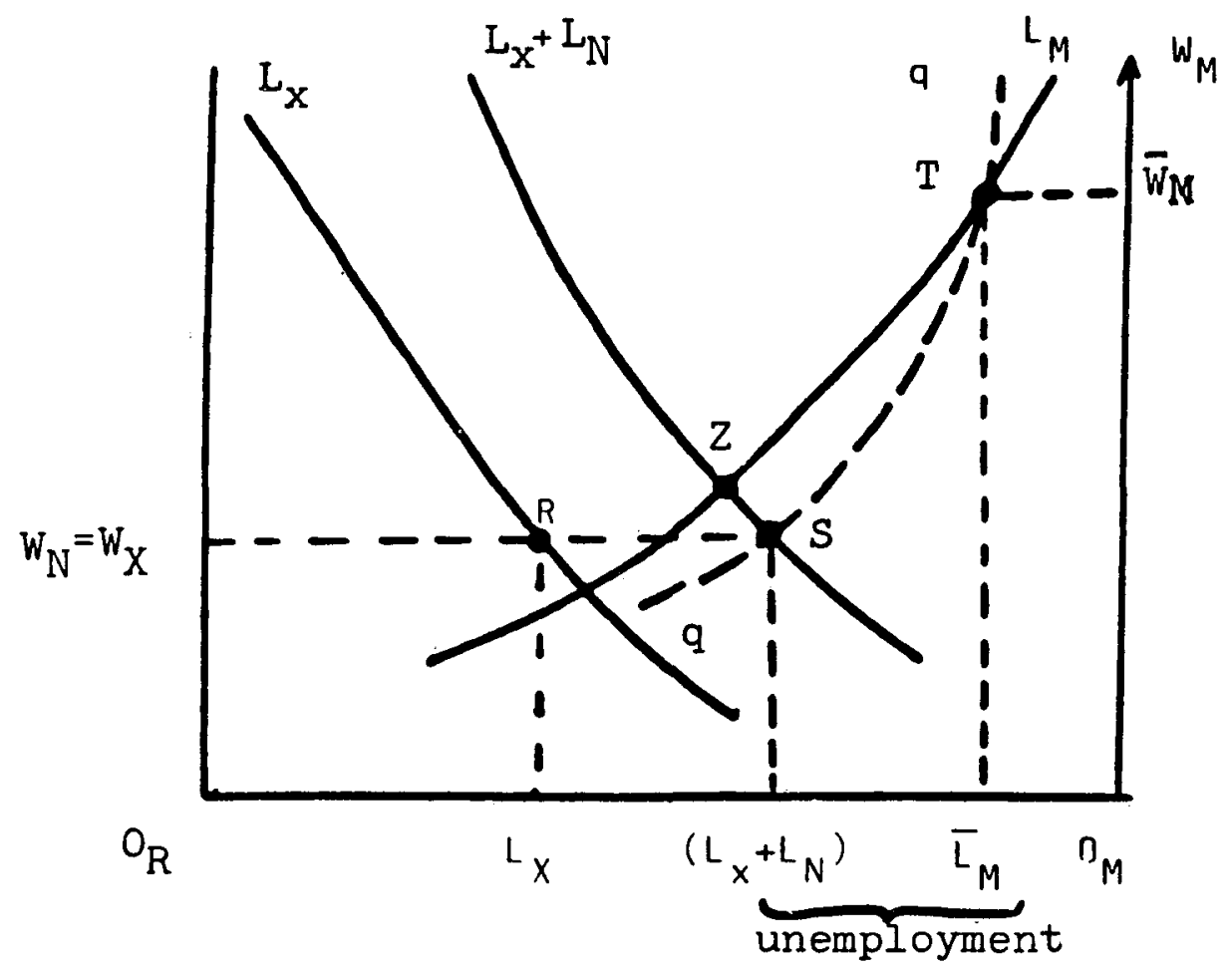


where $U$ is the equilibrium level of unemployment. ${ }^{64}$ In the absence of a minimum wage, the equilibrium is attained at point $z$. With a minimum wage, however, the intersection of $\left(\mathrm{L}_{\mathrm{X}}+\mathrm{L}_{\mathrm{N}}\right)$ with $\mathrm{qq}$ at point $\mathrm{s}$ gives us the wage rate in the uncovered (no minimum wage) sectors, employment in each sector, and total unemployment. $o_{R} L_{X}$ is total employment in the exportables sector; the distance $L_{X}\left(L_{X}+L_{N}\right)$ is employment in nontradables; the distance $\left(\mathrm{L}_{\mathrm{X}}+\mathrm{L}_{\mathrm{N}}\right) \overline{\mathrm{L}}_{\mathrm{M}}$ is the initial equilibrium level of unemployment; and the distance $O_{M} \bar{I}_{M}$ is employment in the covered sector. 65

The short-run (with immobile capital across sectors) effects of a reduction in the import tariff are illustrated in Figure B.2. As a result of the decline in $t$, demand for labor in the importables sector shifts downward. At the given minimum wage, $\overline{\mathrm{W}}_{M}$, total demand for labor in the importables sector will decline. The new demand for labor in that sector (not drawn) will intersect $\bar{W}_{M} T$ at $A$. Now labor demanded by the importables sector is reduced to ${ }^{O}{ }_{M} M^{\prime}$ and a new rectangular hyperbola $q^{\prime} q^{\prime}$ passes through A.

What will happen to wages and employment in the uncovered sectors, and to unemployment? Under the assumption that the price of nontradables remains constant, curve $\left(\mathrm{L}_{\mathrm{X}}+\mathrm{L}_{\mathrm{N}}\right)$ remains at its original location and point $B$, given by the intersection of $q^{\prime} q^{\prime}$ and $\left(L_{X}+L_{N}\right)$, is the new

${ }^{64}$ This formulation, of course, follows from Harris and Todaro's (1970) classical article on migration (see also Harberger (1971b)). For the use of this discussion in the context of a two sector economy see Corden and Findlay (1975) and Neary (1981). For a three sector analysis see Edwards (1988a). Notice that for expositional purposes, the wage rate in importables is assumed to be fixed with respect to exportables. See Neary (1981) for illustration of what will happen if this assumption is changed.

${ }^{65}$ There is an important difference between this type of minimum wage model in which total avallability of labor to the economy is given and models with an upwardly sloping aggregate supply of labor. On this last type of model see Cox-Edwards (1986), and Edwards and Cox-Edwards (1987). 
FIGURE B.2

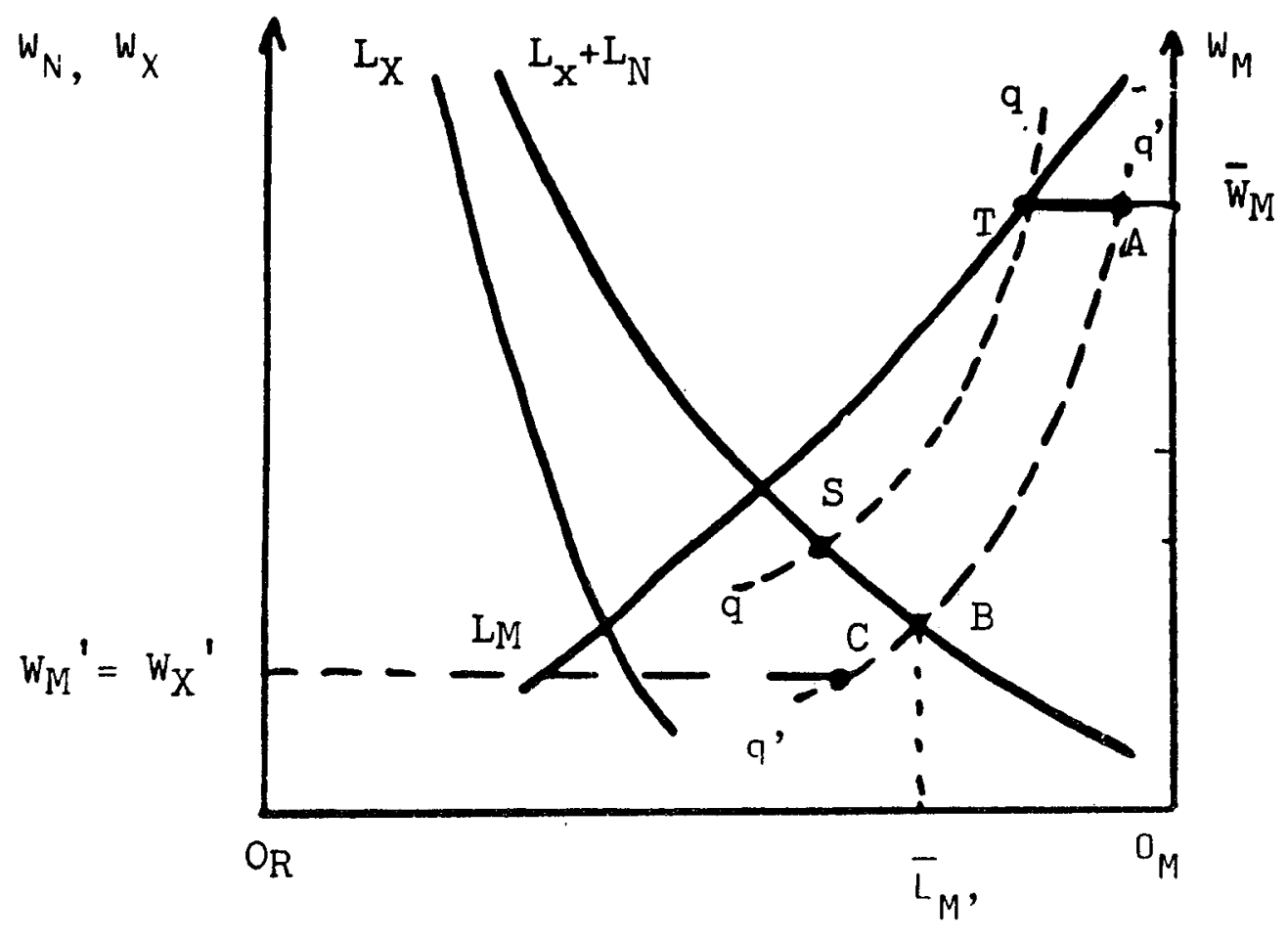


equilibrium. This equilibrium is characterized by a lower wage and higher employment in the uncovered sectors. As discussed above, however, the trade liberalization will affect the price of nontradables and, thus, $\left(L_{X}+L_{N}\right)$ will not remain constant. Under the assumptions discussed above the tariff reduction will generate a reduction in the price of nontradables, which is, however, smaller than the decline in the price of importables. As a result, in the final short-run equilibrium $\left(L_{X}+L_{N}\right)$ will shift downward to $\left(L_{X}+L_{N}\right)^{\prime}$ (not drawn). The intersection of this new $\left(L_{X}+L_{N}\right)^{\prime}$ and the $q^{\prime} q^{\prime}$ rectangular hyperbola at point $C$ is the final equilibrium when capital is locked in its sector of origin.

Thus, in the case in which the non-labor factors are specific, the post-reform equilibrium is characterized by the following: (1) lower employment in the sector covered by the minimum wage (importables): (2) lower wages in the uncovered sectors, expressed in terms of exportables; (3) either higher or lower equilibrium unemployment; (4) either lower or higher employment in nontradables; and (5) higher employment and production in exportables. 66

Not surprisingly, the case of partial minimum wage coverage generates very different results than the case of an economy-wide minimum wage. First, under partial coverage, there is an increase in production and employment in the exportables sector. Second, under partial coverage, employment in nontradables may also increase. Also, in the short run, a tariff reform can result in a reduction in the equilibrium level of

${ }^{66}$ In this setting, unemployment is given by $U-L_{M}\left(\bar{W}_{M} / W_{N}-1\right)$. Because $L_{M}$ declines and $\bar{W}_{M} / W_{W}$ goes up, it is not possible to know a priori which way $U$ will go. The final direction will depend on the elasticities of demand for labor in each sector. 
unemployment in the case of partial minimum wage coverage, whereas greater unemployment always results after such a shock in the case of an economywide minimum wage.

What will happen in the long run in this case with sector-specific minimum wage? In the short run, after the price of imports has gone down, the real return to (sector-specific) capital will be different across sectors. The terms of trade shock reduces the return to capital in the importables (manufacturing) sector and increases it in the exportables and nontradables sector. Of course, this situation with different real returns to capital cannot continue in the long run. As time goes by, capital will be reallocated, moving out of importables and into the other sectors. In terms of Figure B.1, this means that $L_{M}$ will shift downward - and with it the rectangular hyperbola qq .- while the demand for labor in the uncovered sectors will shift upwards. Moreover, these curves will shift in such a way that the final outcome will be characterized by a higher wage in the absence of wage rigidities.

The final long-run equilibrium will have to satisfy two conditions: the return to capital will be equalized across sectors and the labor market will be in equilibrium, in the sense that $W_{N}=W_{X}-\left(L_{M} /\left(L_{M}+U\right)\right) \bar{w}_{M}$. As capital is reallocated, employment in the importables sector declines and employment in the exportables and nontradables sectors increases in relation to the short-run levels depicted in Figure B.1. It is not possible, however, to know a priori whether wages in the uncovered sectors (nontradables and exportables) will be higher or lower in the long run than their initial levels. This will depend on the elasticities of substitution and on the relation between the slopes of the $L_{M}, q q$, and $\left(L_{X}+L_{N}\right)$ curves. 
BIBLIOGRAPHY

Aizenman, Joshua and Jacob A. Frenkel, "Wage Indexation, Supply Shocks, and Monetary Policy in a Small, Open Economy," in S. Edwards and L. Ahamed, eds., Economic Adjustment and Exchange Rates in Developing Countries, Chicago: University of Chicago Press, 1986.

Balassa, Bela The Process of Industrial Development and Alternative Development Strategies, Princeton Essays in International Finance no. 141, Princeton: Princeton Unfversity Press, December 1980. , Development Strategies in Semi-Industrial Economies, Oxford:

Oxford University Press, 1982a. , "Structural Adjustment Policles in Developing Countries," World Development, January 1982b, 10, 114-36. , "The Interaction of Domestic Distortions With Development

Strategies," World Bank Development Research Department, Discussion Paper no. 249 , February $1987 a$. , "The Effects of Exchange Rate Changes in Developing Countries,"

World Bank Development Research Department, Discussion Paper no. 291, May 1987b.

Baghwati, Jagdish. Anatomy and Consequences of Exchange Control Regimes, New York: National Bureau of Economic Research, 1978. , ed., Import Competition and Response, Chicago: University of Chicago Press, 1982. , "Export-Promoting Trade Strategy: Issues and Evidence," World Bank Research Observer, January $1988,3$. Bhandari, Jagdeep, "Trade Reform Under Partial Currency Convertibility: Some Suggestive Results," IMF Working Paper WP/88/69, August 1988. 
Bhattacharya, A., and J. Linn, "Trade and Industrial Policies in the Developing Countries of East Asia," World Bank Discussion Paper No. 27; Washington, DC, 1988 .

Blejer, Mario and Silvia Sagari, "The Structure of the Banking Sector and the Sequencing of Financial Liberalization," in M. Connolly and C. Gonzalez, eds., Economic Reform and Stabilization in Latin America, New York: Praeger, 1987.

Brecher, Richard and Jagdish Bhagwati, "Immiserizing Transfers from Abroad," Journal of International Economics, August 1982, 13, 353-64. and Carlos Diaz-Alejandro, "Tariffs, Foreign Capital and Immiserizing Growth, " Journal of International Economics, November 1977, $7,317-22$. and Ronald Findlay, "Tariffs, Foreign Capital and National Welfare with Sector Specific Factors," Journal of International Economics, May 1983, 14, 277-88.

Burda, M. and J. Sachs (1987) "Labor Markets and Unemployment in Germany," NBER Working Paper.

Calvo, Guilermo A., "On the Time Consistency of Optimal Policy in a Monetary Economy, " Econometrica, 1978, 46, 1411-28. "Trying to Stabilize: Some Theoretical Reflections Based on the Case of Argentina," in P. Aspe, et al. (eds.) Einancial Policies and the World Capital Market, University of Chicago Press, 1983. "Fractured Liberalism: Argentina Under Martinez de Hoz,"

Economic Development and Cultural Change, April 1986, 34, no. 3, 511-33. "On the Costs of Temporary Liberalization/Stabilization

Experiments," in M. Connolly and C. Gonzalez, ed., Economic Reform and Stabilization in Latin America, New York: Praeger, 1987. 
, "Servicing the Public Debt: The Role of Expectations," American Economic Review, 18, September 1988.

Chan-Lee, James, David Coe and Menahem Prywes "Microeconomic Changes and Macroeconomic Wage Disinflation in the 1980s," OECD Economic Studies, Spring 1987.

Choski, Armeane and Demetris Papageorgiou (eds.) Economic Liberalization in Developing Countries, Oxford: Blackwe11, 1986.

Clark, Paul, "Step-by-Step Liberalization of a Controlled Economy: Experience in Egypt," unpublished ms., 1986.

Cline, William R., Trade Policy in the 1980s, Washington: Institute for International Economics, 1983.

Connolly, Michael and J. McDermott, eds., The Economics of the Caribbean Basin, New York: Praeger, 1985.

Cooper, Richard N., "Currency Devaluation in Developing Countries," Princeton Essays in International Finance, no. 86, Princeton: Princeton University Press, June 1971.

Corbo, Vittorio, "The Use of the Exchange Rate for Stabilization Purposes:

The Case of Chile," in M. Connolly and C. Gonzalez, eds., Economic Reform and Stabilization in Latin America, New York: Praeger, 1987. , and Jaime de Melo, "Liberalization and Stabilization in the

Southern Cone of Latin America: Overview and Summary," World Development, August, $1985,13,5-15$. and , "Lessons From the Southern Cone Policy

Experiments," World Bank Research Observer, July 1987, 111-43. Corden, W. Max, "Protection and Liberalization: A Review of Analytical Issues," IMF Occasional Paper 54, Washington, DC, August 1987. 
and R. Findlay, "Urban Unemployment, Intersectoral Capital

Mobility and Development Policy," Economica, 42: 59-78, 1975.

Cox-Edwards, Alejandra, "Economic Reform, External Shocks and the Labor

Market: Chile 1974-1983," paper presented at World Bank Conference on

Adjustment of Labor Markets in LDCs, June 1986.

Cuddington, John T., "Capital Flight: Estimates, Issues, and Explanations,"

Princeton Studies in International Finance, no 58, Princeton: Princeton

University Press, 1986.

Cukierman, Alex, S. Edwards and G. Tabellini, "Political Instability and

Seignorage," paper presented at the NBER Conference on Political Economy, 1989 .

de Melo, Jaime, "Financial Reforms, Stabilization, and Growth Under High

Capital Mobility: Uruguay 1974-1983," in M. Connolly and C. Gonzalez, eds., Economic Reform and Stabilization in Latin America, New York:

Praeger, 1987.

Dervis, Kemal, Jaime de Melo and Sherman Robinson, "A General Equilibrium

Analysis of Foreign Exchange Shortages in a Developing Economy," Economic

Journal, December 1981.

Diaz-Alejandro, Carlos F., "Trade Policies and Economic Development," in

P.B. Kenen, ed., International Trade and Finance: Frontiers for

Research, Cambridge,UK: Cambridge University Press, 1975.

, "Southern Cone Stabilization Plans," in W.R. Cline and S.

Weintraub, eds., Economic Stabilization in Developing Countries,

Washington: Brookings Institution, 1981.

, "Good-bye Financial Repression, Hello Financial Crash," Journal

of Development Economics, January 1987, 19, 1-24. 
Dixit, A., "Entry and Exit Decisions of Firms With Fluctuating Real Exchange Rates," Working Paper, Princeton University 1987a. , "Hysteresis, Import Penetration and Exchange Rate Pass Through," Working Paper, Princeton University, $1987 \mathrm{~b}$. , and V. Norman, Theory of International Trade, Cambridge University Press, 1980.

Dornbusch, Rudiger, "Tariffs and Nontraded Goods," Journal of International Economics, August 1974, 177-85. , "Stabilization Policies in Developing Countries: What Have We Learned?" World Development, September 1982, 10, 701-30. , "Real Interest Rates, Home Goods and Optimal External Borrowing," Journal of Political Economy, February 1983a, 91, 141-53. , "Remarks on the Southern Cone," IMF Staff Papers, March 1983b, $30,173-76$.

, "External Debt, Budget Deficits, and Disequilibrium Exchange Rates," in G. Smith and J. Cuddington, eds., International Debt in the Developing Countries, Washington: World Bank, 1985. , "Inflation, Exchange Rates, and Stabilization," Princeton Essays in International Finance no. 165, Princeton: Princeton University Press, 1986. "Notes on Credibility and Stabilization," MIT Working Paper, 1988.

Edwards, Sebastian, "The Order of Liberalization of the External Sector in Developing Countries," Princeton Essays in International Finance no 156 , Princeton: Princeton University Press, December 1984. , "Stabilization with Liberalization: An Evaluation of Ten Years of Chile's Experience with Free Market Policies," Economic Development 
and Cultural Change, January $1985,33,223-54$.

, "Monetarism in Chile, 1973-1983: Some Economic Puzzles,"

Economic Development and Cultural Change, April 1986, 34, 535-59.

, "The Liberalization of the Current and Capital Accounts and the

Real Exchange Rate," NBER Working Paper no. 2162, February 1987a.

, "Economic Liberalization and the Equilibrium Real Exchange Rate

in Developing Countries," NBER Working Paper no. 2179, March 1987b.

, "Sequencing of Economic Liberalization in Developing Countries,"

Finance and Development, March 1987c, 26-29.

, "Terms of Trade, Tariffs and Labor Market Adjustment in

Developing Countries, " World Bank Economic Review, 1988a, 2, 165-85.

, "Structural Adjustment in Highly Indebted Countries," in $\mathrm{J}$.

Sachs (ed.) The Developing Countries Debt Crisis, University of Chicago

Press, 1988b.

- Real Exchange Rates. Devaluation and Adjustment: Exchange Rate

Policy in Developing Countries, MIT Press, 1989a, forthcoming.

"Tariffs, Capital Controls and Equilibrium Real Exchange Rates,"

Canadian Journal of Economics, 22, 1989b.

- "Temporary Terms of Trade Disturbances, Real Exchange Ratés and

the Current Account," Economica, 1989c, forthcoming.

, "Trade Liberalization, Structural Reforms and Labor Market

Adjustment," UCLA Working Paper, 1989d.

- "Macroeconomic Environment and Trade Policies," paper prepared

for World Bank Trade Policy Department, UCLA, 1989e.

, and Llaquat Ahamed, eds., Economic Adjustment and Exchange Rates

in Developing Countries, Chicago: University of Chicago Press, 1986. 
and Alejandra Cox-Edwards, Monetarism and Liberalization: The

Chilean Experiment, Cambridge, MA: Ballinger, 1987.

and Mohsin S. Khan, "Interest Rate Determination in Developing

Countries," IMF Staff Papers, September 1985, 32, 377-403. and Sweder van Wijnbergen, "The Welfare Effects of Trade and

Capital Market Liberalization: Consequences of Different Sequencing

Scenarios," NBER Working Paper no. 1245, December 1983. and , "The Welfare Effects of Trade and Capital Market

Liberalization," International Economic Review, February 1986, 27, 141-48. and , "Tariffs, the Real Exchange Rate and the Terms of

Trade: On Two Popular Propositions in International Economics, " Oxford Economic Papers, 1987a, 39, 458-64. and , "On the Appropriate Timing and Speed of Economic

Liberalization in Developing Countries," in M. Connolly and C. Gonzalez, eds., Economic Reform and Stabilization in Latin America, New York:

Praeger, 1987b. , and Jonathan Ostry "Terms of Trade Disturbances, Real Exchange

Rates and Welfare: The Role of Capital Controls and Labor Market

Distortions," IMF Working Paper WP/89-21, March 1989.

Fischer, S., "Issues in Medium Term Macroeconomic Adjustment," World Bank Qbserver, July 1986. , "Economic Growth and Economic Policy," in V. Corbo (et al.)

Growth-Oriented Adfustment Programs, Washington, DC: IMF-World Bank, 1987.

Frenkel, Jacob A., "The Order of Economic Liberalization: A Comment," in K. Brunner and A.H. Meltzer, eds., Economic Policy in a World of Change, Amsterdam: North-Holland 1982. 
"Remarks on the Southern Cone," IMF Staff Papers, March 1983,

$30,164-73$.

Harberger, Arnold, "Three Basic Principles on Applied Welfare Economics," Journal of Economic Literature, 9, September 1971 a.

"On Measuring the Social Opportunity Cost of Labor," ILO Review,

103 , no. 6: 559-79, $1971 \mathrm{~b}$.

, "The Chilean Economy in the 1970s: Crisis, Stabilization,

Liberalization, Reform," in K. Brunner and A.H. Meltzer, eds., Economic

Policy in a World of Change, Amsterdam: North-Holland, 1982.

, "A Primer on the Chilean Economy," in M. Connolly and C.

Gonzalez, eds., Economic Reform and Stabilization in Latin America, New

York: Praeger, 1987.

Harris, John and M. Todaro, "Migration, Unemployment and Development: A Two

Sector Analysis," American Economic Review, 60: 126-142, 1970.

Johnson, Harry G., "Optimal Trade Intervention in the Presence of Domestic

Distortions," in R. Caves et al., eds., Trade. Growth, and Balance of

Payments, Chicago: Rand McNally, 1965.

, "The Possibility of Income Losses From Increased Efficiency or

Factor Accumulation in the Presence of Tariffs, " Economic Journal, 1967,

$77,151-54,1967$.

Khan, Mohsin S., "Macroeconomic Adjustment in Developing Countries: A Policy

Perspective," World Bank Research Observer, January 1987, 2, 23-42. and Malcolm D. Knight, "Stabilization Programs in Developing

Countries: A Formal Framework," IMF Staff Papers, March 1981, 28, 1-53. and Roberto Zahler, "The Macroeconomic Effects of Changes in

Barriers to Trade and Capital Flows: A Simulation Analysis, " IMF Staff

Papers, June 1983, 30, 223-82. 
and "Trade and Financial Liberalization Given

External Shocks and Inconsistent Domestic Policies," IMF Staff Papers, March 1985, 32, 22-55. and "The Liberalization of Trade and Capital Flows in

Developing Countries: Some Theoretical and Empirical Issues," in M.

Connolly and C. Gonzalez, eds., Economic Reform and Stabilization in

Latin America, New York: Praeger, 1987.

Kiguel, Miguel A., and Jose S. Lizondo, "Theoretical and Policy Aspects of Dual Exchange Rate Systems," World Bank Development Research Department Discussion Paper no. 201, October 1986.

Kim, K.S., and D.F. Ruccio, eds., Debt and Development in Latin America, Notre Dame: University of Notre Dame Press, 1985.

Krueger, Anne 0., Foreign Trade Regimes and Economic Development:

Liberalization Attempts and Consequences, New York: National Bureau of Economic Research, 1978. , "Interactions Between Inflation and Trade-Regime Objectives in Stabilization Programs," in W.R. Cline and S. Weintraub, eds., Economic Stabilization in Developing Countries, Washington: Brookings Institution, 1981. , "Problems of Liberalization," in A. Harberger, ed., World

Economic Growth, San Francisco: ICS Press, 1984. , "How to Liberalize a Small Open Economy?" in M. Connolly and J. McDermott, eds., The Economics of the Caribbean Basin, New York: Praeger, 1985. , "Problems of Liberalization," in A. Choski and D. Papageorgiou (eds.) Economic Liberalization in Developing Countries, oxford: Blackwell, 1986. 
"Resolving the Debt Crisis and Restoring Developing Countries'

Creditworthiness," paper presented at the Carnegie-Rochester Public

Policy Conference, Univ. of Rochester, April 1988.

Kydland, F.E., and E.C. Prescott, "Rules Rather Than Discretion: The Time

Inconsistency of Optimal Plans," Journal of Political Economy, 1977, 85, 473-92, 1977.

Lal, Deepak, "The Real Aspects of Stabilization and Structural Adjustment Policies: An Extension of the Australian Adjustment Model," World Bank Staff Working Paper no. 636, March 1985. "Comment," in A. Choski and D. Papageorgiou (eds.) Economic

Liberalization in Developing Countrles, Oxford: Basil Blackwell, 1986. and Sarath Rajapatirana, "Foreign Trade Regimes and Economic

Growth in Developing Countries," World Bank Research Observer, July 1987, 2 , $189-218$.

Leamer, Edward E., "Welfare Computations and the Optimal Staging of Tariff Adjustments in Models with Adjustment Costs," Journal of International Economics, February 1980, 10, 21-36. , "Paths of Development in the Three-Factor, N-Goods General

Equilibrium Mode1," Journal of Political Economy, 95, October 1987. Little, Ian, Tibor Scitovsky, and Maurice Scott, Industry and Trade in Some Developing Countries: A Comparative Study, London: Oxford University Press, 1970.

Mathieson, Donald J., "Financial Reform and Capital Flows in a Developing Economy," IMF Staff Papers, September 1978, 25, 450-89. and R. Mckinnon, "How to Manage a Repressed Economy," Princeton Essays in International Finance, no. 145, Princeton: Princeton University Press, December 1981. 
Mayer, Wolfgang, "Short Run and Long Run Equilibrium for a Small Open Economy," Journal of Political Economy, 82, 1974.

McKinnon, Ronald I., Money and Capital in Economic Development, Washington: Brookings Institution, 1973. , "International Transfers and Non-traded Commodities: The Adjustment Problem," in D.M. Leipziger, ed., The International Monetary System and the Developing Nations, Washington: Agency for International Development, 1976. , "Foreign Trade Regimes and Economic Development: A Review Article," Journal of International Economics, 1979, 9, 429-52. , "The Order of Economic Liberalization: Lessons from Chile and Argentina," in K. Brunner and A.H. Meltzer, eds., Economic Policy in a World of Change, Amsterdam: North Holland, 1982. - "The International Capital Market and Economic Liberalization in IDCs," The Developing Economies, December 1984, 22. Michaely, Michael, "Exports and Growth: An Empirical Investigation," Journal of Development Economics, March 1977, 4, 49-54. , "The Sequencing of Liberalization Policies: A Preliminary Statement of Issues," unpublished paper, 1982. "Trade Liberalization Policies: Lessons of Experience," paper presented at the conference "For a New Policy Towards Forelgn Trade," Braz11, Apri1 1987. Armeane Choski and D. Papageorglou, "The Phasing of a Trade Liberalization Pollcy: Preliminary Evidence," paper presented at the Annual Meeting of the American Economic Association, New Orleans, Dec. 1986. 
Mussa, Michael, "Tariffs and the Distribution of Income: The Importance of Factor Specificity," Journal of Political Economy, November 1974, 82, $1191-203$.

, "Dynamic Adjustment in the Heckscher-Ohlin-Samuelson Model," Journal of Political Economy, 86, 1978. , "Government Policy and the Adjustment Process," in J. Bhagwati, ed., Import Competition and Response, Chicago: University of Chicago Press, 1982.

, "The Adjustment Process and the Timing of Economic

Liberalization," NBER Working Paper no. 1458, September 1984. , Macroeconomic Policy and Trade Liberalization: Some

Guidelines, " World Bank Research Observer, January 1987, 2, 61-78. Neary, Peter, "Short-Run Capital Specificity and the Pure Theory of International Trade," Economic Journal, September 1978, 88, 448-510. , "On the Harris-Todaro Model With Intersectoral Mobility,"

Economica 48: $219-234,1981$. , "Capital Mobility, Wage Stickiness and the Case for Adjustment

Assistance," in J. Bhagwati, ed., Import Competition and Response,

Chicago: University of Chicago Press, 1982. , "International Factor Mobility, Minimum Wages and Factor Price Equalization: A Synthesis," Quarterly Journal of Economics, 1985, 100. Obstfeld, Maurice, "Capital Flows, the Current Account and the Real Exchange

Rate: The Consequences of Stabilization and Liberalization, " in S.

Edwards and L. Ahamed, eds., Economic Adjustment and Exchange Rates in Developing Countries, Chicago: University of Chicago Press, 1986. Rodriguez, Carlos A., "Politicas de Estabilizacion en la Economia Argentina 1978-1982," Cuadernos de Economia, Apríl 1983, 19, 322-40. 
Rodrik, Dani, "Trade and Capital Account Liberalization in a Keynesian Economy," Journal of International Economics, August 1987, 23. , "Liberalization, Sustainability and the Design of Structural Adjustment Programs," J.F. Kennedy School, Harvard, Working Paper \#177D, 1989.

Sachs, J., "Trade and Exchange Rate Policies in Growth-Oriented Adjustment Programs," in V. Corbo, et al. (eds.) Growth-Oriented Adjustment Programs IMF-World Bank, 1987. , "Conditionality, Debt Relief and the Developing Countries' Debt Crisis," NBER Working Paper No. 2644, 1988.

Sargent, Thomas, "Stopping Moderate Inflations: The Methods of Poincare and .Ms. Thatcher," in T. Sargent Rational Expectations and Inflation, Harper and Row, 1986.

Se11, Friedich, "True Exposure: The Analysis of Trade Liberalization in a General Equilibrium Framework," Weltwirtschaftliches Archiv Band 124, Heft 4, 1988.

Sjaastad, Larry A., "Failure of Economic Liberalization in the Southern Cone of Latin America," World Economy, March 1983, 6, 5-27.

Smith, G., and J. Cuddington, eds., International Debt in the Developing Countries, Washington: World Bank, 1985.

Stiglitz, Joseph and Andrew Weiss, "Credit Rationing in Markets with Imperfect Information," American Economic Review, 1981, 71, 393-410. Stockman, Allan, "The Order of Liberalization: Comment," in K. Brunner and A. Meltzer (eds.), Economic Policy in a World of Change, Amsterdam: North-Holland 1982.

Svensson, Lars, "Oil Prices, Welfare and the Trade Balance," Quarterly Journal of Economics, 99: 649-72, November 1984. 
and A. Razin, "The Terms of Trade and the Current Account: The Harberger-Laursen-Meltzer Effect," Journal of Political Economy, 91: 97125, February 1983.

van Wijnbergen, Sweder, "Interdependence Revisited: A Developing Countries

Perspective on Macroeconomic Management and Trade Policy in the

Industrial World," Economic Policy, November 1985, 1, 81-114.

"On the Macroeconomic Aspects of Foreign Aid: The Two-Gap Model

Revisited," Journal of International Economics, July 1986. 


\section{ECONOMIC AND STATISTICS DEPARTMENT}

\section{WORKING PAPERS}

In April 1983, the Economics and Statistics Department initiated a new series of economic studies entitled ESD Working Papers.

The following titles have been circulated:

1. Use of Demand Elasticities in Estimating Energy Demand (out of print) Utilisation des élasticités de la demande dans l'estimation de la demande de l'énergie

\section{Axel Mittelstädt}

2. Capital, Energy and Labour Substitution: The Supply Block in OECD Medium-Term Models

Substitution du capital, de l'énergie et du travail : le bloc de l'offre dans les modèles à moyen terme de l'OCDE (épuisé)

\section{Patrick Artus}

3. Wage Formation in France: Sectoral Aspects (out of print)

Formation des salaires en France : aspects sectoriels (épuisé)

\section{Patrick Artus}

4. Service Lives of Fixed Assets (out of print)

Durée de vie utile des actifs fixes (épuisé)

\section{Derek Blades}

5. Resource Prices and Macroeconomic Policies: Lessons from Two 0il Price Shocks

Prix des ressources naturelles et politique macro-économique : les enseignements de deux chocs pétroliers (épuisé)

John Llewellyn

6. Output Responsiveness and Inflation: An Aggregate Study Souplesse de la production et inflation : étude globale

David T. Coe and Gerald Hol tham 
7. The Determinants of Exchange Rate Movements (out of print)

Les déterminants des mouvements des taux de change (épuisé)

Graham Hacche

8. Simulated Macroeconomic Effects of a Large Fall in 0il Prices (out of print)

Simulation des effets macro-économiques d'une forte baisse des prix pétroliers

Flemming Larsen and John Llewellyn

9. Medium-Term Financial Strategy: The Co-ordination of Fiscal Monetary Policy (out of print)

Stratégie financière à moyen terme : la coordination des politiques monétaire et budgétaire (épuisé)

Jean-Claude Chouraqui and Robert Price

10. Price Dynamics and Industrial Structure: A Theoretical and Econometric Analysis (out of print)

Dynamique des prix et structure industrielle : une analyse théorique économétrique (épuisé)

David Encaoua (with collaboration from Paul Geroski and Riel Miller)

11. Evidence on Income Distribution by Governments (out of print)

L'Action exercée par l'Etat sur la redistribution du revenu

\section{Peter Saunders}

12. Labour Force Participation: An Analysis with Projections

Taux d'activité : analyse et projections

James H. Chan-Lee

13. The Demand for Money and Velocity in Major OECD Countries (out of print)

La demande de monnaie et la vitesse de circulation dans les grands pays de l'OCDE

A. Blundell-Wignall, M. Rondoni and H. Ziegelschmidt

14. The Conduct of Monetary Policy in the Current Recovery

La conduite de la politique monétaire dans la phase actuelle de reprise économique

Paul Atkinson and Jean-Claude Chouraqui 
15. Structural Budget Deficits and Fiscal Stance (out of print)

Déficits budgétaires structurels et orientation de la politique budgétaire (épuisé)

Patrice Muller and Robert W.R. Price

16. Monetary Policy in the OECD INTERLINK Model

La politique monétaire dans le modèle INTERLINK

A. Blundell-Wignall, M. Rondoni, H. Ziegelschmidt and J. Morgan

17. Real Gross Product in OECD Countries and Associated Purchasing Power Parities (out of print)

Produit brut réel et parités de pouvoir d'achat dans les pays de l'OCDE (épuisé)

Peter Hill

18. The OECD Compatible Trade and Production Data Base (out of print) Base de données compatibles sur le commerce et la production de l'OCDE

Derek Blades and Wendy Simpson

19. Nominal Wage Determination in Ten OECD Economies

Détermination des salaires nominaux dans dix économies de l'OCDE

David T. Coe and Francesco Gagliardi

20. Profits and Rates of Return in OECD Countries

Profits et taux de rendement dans les pays Membres de l'OCDE

James H. Chan-Lee and Helen Sutch

21. Real Interest Rates and the Prospects for Durable Growth

Taux d'intérêt réels et perspectives de croissance durable

Paul Atkinson and Jean-Claude Chouraqui

22. Energy Prices: Trends and Prospects

Les prix de l'energie : évolution et perspectives

Axel Mittelstädt 
23. Changes in the Composition of output and Employment

Changements dans la composition de la production et de l'emploi

Axel Mittelstädt and Françoise Correia

24. Labour Market Flexibility and External Price Shocks

Flexibilité du marché du travail et chocs extérieurs sur les prix

F. Klau and A. Mittelstädt

25. Discrepancies Between Imports and Exports in OECD Foreign Trade Statistics (out of print)

Ecart entre les importations et les exportations dans les statistiques du commerce extérieur de l'OCDE

Derek Blades and Marina Ivanov

26. Aggregate Supply in INTERLINK: Model Specification and Empirical Results

John Helliwell, Peter Sturm, Peter Jarrett and Gérard Salou

27. Commodity Prices in INTERLINK

Gerry Holtham, Tapio Saavalainen, Paul Saunders and Helen Sutch

28. Exchange Rates and Real Long-Term Interest Rate Differentials: Evidence for Eighteen OECD Countries

David T. Coe and Stephen S. Golub

29. Method of Calculating Effective Exchange Rates and Indicators of Competitiveness (out of print)

Martine Durand

30. Public Debt in a Medium-Term Context and its Implications for Fiscal Policy

Jean-Claude Chouraqui, Brian Jones and Robert Bruce Montador

31. The OECD Compatible Trade and Production Data Base 1970-1983

Anders Brodin and Derek Blades 
32. The Formulation of Monetary Policy: A Reassessment in the Light of Recent Experience

Paul Atkinson and Jean-Claude Chouraqui

33. Mécanismes de transmission et effets macro-économiques de la politique monétaire en France : les principaux enseignements econométriques

Marc-Olivier Strauss-Kahn

34. Pure Profit Rates and Tobin's $q$ in Nine OECD Countries James H. Chan-Lee

35. Wealth and Inflation Effects in the Aggregate Consumption Function G.H. Hol tham and H. Kato

36. The Government Household Transfer Data Base $\underline{\text { Rita Varley }}$

37. Internationalisation of Financial Markets: Some Implications for Macroeconomic Policy and for the Allocation of Capital

Mitsuhiro Fukao and Masaharu Hanazaki

38. Tracking the US External Deficit, 1980-1985: Experience with the OECD INTERLINK Model

Pete Richardson

39. Monetary Policy in the Second Half of the 1980s: How Much Room For Manoeuvre?

Kevin Clinton and Jean-Claude Chouraqui

40. Tax Reform in OECD Countries: Economic Rationale and Consequences Bob Hagemann, Brian Jones and Bruce Montador

41. A Revised Supply Block for the Major Seven Countries in INTERLINK Peter Jarrett and Raymond Torres 
42. OECD Economic Activity and Non-0il Commodity Prices: Reduced-Form Equations for INTERLINK

Gerald Holtham and Martine Durand

43. Import and Export Price Equations for Manufactures

Richard Herd

44. Price Determination in the Major Seven Country Models in INTERLINK Ulrich Stiehler

45. International Investment-Income Determination in INTERLINK: Models for 23 OECD Countries and Six Non-OECD Regions

David T. Coe, Richard Herd and Marie-Christine Bonnefous

46. Recent Developments in OECD's International Macroeconomic Model Pete Richardson

47. A Review of the Simulation Properties of OECD's INTERLINK Model Pete Richardson

48. The Medium-Term Macroeconomic Strategy Revisited Jean-Claude Chouraqui, Kevin Clinton and Robert Bruce Montador

49. Are Commodity Prices Leading Indicators of OECD Prices? Martine Durand, Sveinbjörn Blöndal

50. Private Consumption, Inflation and the "Debt Neutrality Hypothesis" The case of Eight OECD Countries

Giuseppe Nicoletti

51. The Effects of Monetary Policy on the Real Sector: An overview of Empirical Evidence for Selected OECD Economies

Jean-Claude Chouraqui, Michael Driscoll and Marc Olivier Strauss-Kahn 
52. The So-Called "Non-Economic" Objectives of Agricultural Policy L. Alan Winters

53. Alternative Solution Methods in Applied General Equilibrium Analysis

Richard G. Harris

54. Tests of Total Factor Productivity Measurement

A. Steven Englander

55. Quantifying the Economy-Wide Effects of Agricultural Policies: A General Equilibrium Approach

Jean-Marc Burniaux, François Delorme, Ian Lienert, John P. Martin and Peter Hoeller

56. On Aggregation Methods of Purchasing Power Parities

J.R. and M. Cuthbert

57. An International Sectoral Data Base for Thirteen OECD Countries F.J.M. Meyer-zu-Schlochtern

58. Empirical Research on Trade Liberalisation with Imperfect Competition: A Survey

\section{J. David Richardson}

59. Eliminating the US Federal Budget Deficit by 1993: the Interaction of Monetary and Fiscal Policy

$\underline{\text { R. Herd and B. Ballis }}$

60. Compatible Trade and Production Data Base: 1970-1985

Claude Berthet-Bondet, Derek Blades and Annie Pin 
61. Ageing Populations: Implications for Public Finances Robert P. Hagemann, Giuseppe Nicoletti

62. The Economic Dynamics of an Ageing Population: the Case of Four OECD Economies

Alan J. Auerbach, Laurence J. Kotlikoff, Robert P. Hagemann, Giuseppe Nicoletti

63. Modelling Housing Investment for Seven Major OECD Countries Thomas Egebo and Ian Lienert

64. Revised Groupings for non-OECD Countries in OECD's macroeconomic model INTERLINK

Paul $0^{\prime}$ Brien, Laure Meuro, Arthur Camilleri

65. A Post Mortem on OECD Short-Term Projections from 1982 to 1987

Byron Ballis

66. Potential Output in the Seven Major OECD Countries

Raymond Torres and John P. Martin

67. Saving Trends and Behaviour in OECD Countries

Andrew Dean, Martine Durand, John Fallon and Peter Hoeller

68. The Impact of Increased Government Saving on the Economy Richard Herd

69. The Information Content of the Terms Structure of Interest Rates: Theory and Practice

Frank Browne and Paolo Manasse 